\title{
Pro-poor indirect tax reforms, with an application to Mexico*
}

\author{
Abdelkrim Araar \\ Jean-Yves Duclos \\ Paul Makdissi,
}

Abdelkrim ARAAR, is Professor at the Department of economics at Laval University. He is also member of PEP-Politiques économiques et pauvreté- and CIRPEE. Email: aabd@ecn.ulaval.ca

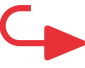

Jean-Yves DUClOS is Director and full Professor at the Department of economics at Laval University. He is also member of CIRPEE- Centre interuniversitaire sur le risque, les politiques économiques et l'emploi. He is Senior Fellow at Ferdi. Email: jyves@ecn.ulaval.ca

PAUl MAKDISSI, is Professor at the Department of economics at University of Ottawa. Email: paul.makdissi@uottawa.ca

\section{Abstract}

This paper proposes a methodology for testing for whether tax reforms are pro-poor. This is done by extending stochastic dominance techniques to identify tax reforms that will be deemed absolutely or relatively pro-poor by a wide spectrum of poverty analysts. The statistical properties of the various estimators are also derived in order to make the method implementable using survey data. The methodology is used to assess the pro-poorness of possible reforms to Mexico's indirect tax system. This leads to the identification of several possible pro-poor tax reforms in that country. It also shows how the pro-poorness of a tax reform depends on one's conception of poverty as well as on the revenue and efficiency impact of the reform.

\footnotetext{
JEL: D12, D63, H21, I32.

Keywords: Stochastic dominance, pro-poor changes, tax reforms, Mexico

* This work was carried out with support from SSHRC, FQRSC and the Poverty and Economic Policy Research Network, which is financed by the Government of Canada through the International Development Research Centre and the Canadian International Development Agency, and by the Australian Agency for International Development. We are grateful to Sami Bibi for useful comments and to Lourdes Trevio and Jorge Valero Gil for having facilitated access to the ENIGH data, for their invitation to present this paper at the Eight Symposium on "Capital Humano, Crecimiento, Pobreza: Problemàtica Mexicana" held in Monterrey, Mexico in October 2006, and for having made available a preliminary version of this paper in the Symposium proceedings - see Audet et al. (2007).
} 


\title{
Pro-poor indirect tax reforms, with an application to Mexico *
}

\author{
Jean-Yves Duclos ${ }^{\dagger}$ Paul Makdissi $;$ and Abdelkrim Araar ${ }^{\S}$
}

11th November 2012

\begin{abstract}
This paper proposes a methodology for testing for whether tax reforms are pro-poor. This is done by extending stochastic dominance techniques to identify tax reforms that will be deemed absolutely or relatively pro-poor by a wide spectrum of poverty analysts. The statistical properties of the various estimators are also derived in order to make the method implementable using survey data. The methodology is used to assess the pro-poorness of possible reforms to Mexico's indirect tax system. This leads to the identification of several possible pro-poor tax reforms in that country. It also shows how the pro-poorness of a tax reform depends on one's conception of poverty as well as on the revenue and efficiency impact of the reform.

Keywords: Stochastic dominance, pro-poor changes, tax reforms, Mexico. JEL Codes: D12, D63, H21, I32.

*This work was carried out with support from SSHRC, FQRSC and the Poverty and Economic Policy Research Network, which is financed by the Government of Canada through the International Development Research Centre and the Canadian International Development Agency, and by the Australian Agency for International Development. We are grateful to Sami Bibi for useful comments and to Lourdes Trevio and Jorge Valero Gil for having facilitated access to the ENIGH data, for their invitation to present this paper at the Eight Symposium on "Capital Humano, Crecimiento, Pobreza: Problemática Mexicana" held in Monterrey, Mexico in October 2006, and for having made available a preliminary version of this paper in the Symposium proceedings - see

$\dagger$ Département d'économique and CIRPÉE, Université Laval, Canada, and FERDI; email:

${ }_{\ddagger}^{\ddagger}$ Department of Economics, University of Ottawa, Canada; Email: paul.makdissi@uottawa.ca

§PEP and CIRPÉE, Pavillon de Sève, Université Laval, Canada; Email: aabd@ecn.ulaval.ca
\end{abstract} Audet et al. (2007). jyves@ecn.ulaval.ca 


\section{Introduction}

Recent policy objectives have often focused on improving the welfare of the less fortunate in society. There are several reasons for this: some are related to a rise in the ethical and policy importance of poverty reduction (best exemplified by the salience of the United Nations' Millennium Development Goals), while others are linked to more specific conditions, such as concerns for the effect on the poor of food price variability and of the recent global financial and economic crisis.

Signs of such policy interest abound, in particular regarding the use of indirect taxation and price subsidies as tools for poverty alleviation. For instance, a report from an initiative recently launched by the UNDP, the Government of China and DFID states that "the depth and coverage of China's fiscal reform process has been uneven, and there is scope for strengthening the links between fiscal reforms and poverty reduction goals." ${ }^{1}$ Commentators in the Philippines have argued that the "fiscal crisis hurts the poor Filipinos more than it hurts the rich and the big corporations. [...] Only a pro-poor management of the fiscal crisis will make Filipinos rally behind the Arroyo administration during this difficult time." ${ }^{2}$ One element of the reaction of the Filipino government has indeed been to expand the use of the Value Added Tax (VAT) because it claimed that "its burden falls heavier on those who consume more "VATable' goods and services."3

In India, the press has "wanted Finance minister P. Chidambaram to balance tight fiscal policy with pro-poor policies". ${ }^{4}$ The 2008 Pakistan budget has also been criticized because it "was hoped that the current government would realize that achieving fiscal discipline and increasing revenues is important, but not on the backs of the poor. If the government wants to address the challenges of inflation, rising inequality and poverty, it must devise a progressive taxation policy that relies less on indirect taxes and more on increasing the tax-GDP ratio by extending the tax net to untaxed sectors."

Concerns for the poverty effect of government financing procedures have also extended to other areas, such as how health care financing systems can be designed and implemented to be "pro-poor" (see for instance Bennett and Gilson 2001). This naturally suggests the broader policy problem of using a tax and expenditure

\footnotetext{
${ }^{1}$ http://www.undp.org.cn/projects/39815.pdf.

$2 \mathrm{http} / / /$ aupwu.blogspot.com/2004/11/pro-poor-response-to-fiscal-crisis.html.

${ }^{3}$ http://www.sunstar.com.ph/static/dav/2006/02/13/bus/expanded.vat.is.pro.poor.solon.html.

${ }^{4} \mathrm{http}$ //www.financialexpress.com/news/fm-should-balance-policy-with-propoor-plansfitch/127916/.

${ }^{5}$ http://www.opfblog.com/2901/is-pakistan-budget-2008-pro-poor-by-sadia-m-malik/.
} 
system to minimize poverty subject to some government budget constraint. As is well-known, an overriding tradeoff in such problems is to balance potential gains in equity and in efficiency.

The last decade has also seen several conceptual and empirical contributions on whether growth is "pro-poor". A central issue is whether the poor's benefits from growth exceed some norm - see, among many recent interesting contributions to that issue, Bruno, Ravallion, and Squire (1998), United Nations (2000), Eastwood and Lipton (2001), Ravallion (2001), Dollar and Kraay (2002), World Bank (2002) and Bourguignon (2003). This norm may be absolute or relative to the changes in the entire distribution of income, as discussed for example in Duclos (2009) and Klasen (2008). In addition, Klasen (2008) distinguishes between strong and weak absolute pro-poor norms. An absolute norm is said to be weak if it requires only that poverty decreases. It is labeled as strong if the absolute income gain of the poor is larger than the average one.

For instance, the weak absolute pro-poor view will consider as equally propoor two changes to an income distribution, a first one that increases by $\$ 1$ the incomes of everyone, and a second one that increases by $\$ 1$ the incomes of the poor and by $\$ 10,000$ the incomes of everyone else. This is because the weak absolute pro-poor view attaches no weight to the relative impact of distributional changes, and that it also incorporates an absolute definition of the poverty line. The weak absolute pro-poor view is consistent with the Pareto criterion: any increase in income cannot increase poverty and must therefore be considered to be absolutely pro-poor.

Conversely, the relative pro-poor view judges as equally pro-poor two changes in an income distribution, a first one by which everyone's income falls by 50 percent, and a second one by which everyone's income increases by 50 percent. This is because the relative pro-poor view focusses exclusively on the relative impact of income changes. According to this relative pro-poor view, a Paretoimproving tax reform is not necessarily pro-poor since it may worsen inequality in the distribution of incomes. The latter two views are well illustrated in a collection of "one-pagers" produced by UNDP (2009).

Finally, the strong absolute pro-poor view judges as equally pro-poor two changes in an income distribution, a first one by which everyone's income falls by $\$ 1$, and a second one by which everyone's income increases by $\$ 1$. The main difference with the relative pro-poor view is that the strong absolute pro-poor view focusses on the difference between the absolute gain (or loss) of the poor compared to the average absolute gain (or loss). As in the relative pro-poor case, this view does not consider all Pareto-improving tax reforms as pro-poor since it 
requires that the poor gain by at least as much as the average gain.

A similar issue applies to the effect of public policy in general. As is clear from the above, we may wish for instance to assess whether a fiscal reform is "pro-poor", in the sense that the benefits that the poor derive from it exceed some norm. Unfortunately, as with many other distributive assessments, the precise definition that can be given to the pro-poorness of a tax reform is essentially a matter of normative judgement and can be open to the criticism of being arbitrary at least to some extent. Apart from the choice between absolute and relative pro-poor views, elements of arbitrariness arise inter alia in the selection of a poverty line to separate the poor from the non-poor and in the choice of an aggregative procedure to summarize the reform's impact on the poor. ${ }^{6}$ To show how one can reduce these sources of arbitrariness in understanding pro-poorness is the first main objective of this paper. To do this, we concentrate on the relative and strong absolute propoor views (to which we simply refer from now onwards as the absolute pro-poor view). The case of the weak absolute pro-poor views has been extensively analyzed in Makdissi and Wodon (2002) and Duclos, Makdissi, and Wodon (2008).

The second main objective of the paper is to assess how a (marginal) tax reform can be considered to be pro-poor. Santoro (2007) separates the economic literature on the impact of marginal tax reforms into three different branches. The first type draws from Ahmad and Stern (1984) and uses a specific social welfare function. The impact on social welfare of a marginal tax reform is then obtained by taking the derivative of the social welfare function with respect to the price of the good that is being changed by the tax reform. The second branch of the literature identifies directions for marginal tax reforms based on classes of social welfare functions that display an aversion to inequality and that are symmetric. These functions are called second-order social welfare functions, and were originally used for a marginal tax reform purpose by Yitzhaki and Thirsk (1990), Yitzhaki and Slemrod (1991) and Mayshar and Yitzhaki (1996). "Welfare-improving tax reforms" are then identified by assessing whether a tax reform can be deemed to increase social welfare according to all of those second-order social welfare functions. The third branch extends this by recognizing that governments may also want to use marginal tax reforms in order to improve other sorts of social evaluation functions, such as poverty indices and social welfare functions that may or

\footnotetext{
${ }^{6}$ Different approaches have been proposed to separate the poor from the non-poor and to compute indices of "growth pro-poorness". See, for instance, McCulloch and Baulch (1999), Ravallion and Datt (2002), Kakwani, Khandker, and Son (2003), Ravallion and Chen (2003), Klasen (2004), Son (2004), Essama-Nssah (2005), Araar, Duclos, Audet, and Makdissi (2007) and Kakwani and Son (2008).
} 
may not be averse to inequality. The tools that are then used draw inter alia from Makdissi and Wodon (2002), Duclos, Makdissi, and Wodon (2008) and Liberati (2003).

This paper extends this third branch of the literature by testing for whether indirect tax reforms can be considered to be pro-poor. By this, it is meant that an indirect tax reform must be deemed to be "equitable towards the poor" or "in favor of the poor", in the sense that the benefits of the reform must accrue (in some sense to be made precise later) "more" to the poor, or that its costs must hurt "less" the poor.

The first and second main objectives are dealt with in Section 2. The results are general enough to cover the cases of negative (subsidies) and positive indirect taxation, and of tax reforms that may or may not be revenue and/or efficiency neutral. Although for expositional simplicity the paper focusses on indirect tax changes, the methodology can be relatively easily adapted to deal with the effect of changes in direct taxation and in-kind benefits. Section 2 further hints to how the paper's framework and analytical results can also be used to assess the impact of tax reforms on absolute and relative inequality.

The analytical results of Section 2 show that whether tax reforms involving only one good are pro-poor depend roughly on whether the good is an inferior, a necessary, or a luxury one. More generally, the pro-poorness of a tax reform depends on a mixture of income (for redistribution) and price (for efficiency) elasticities that are easily combined to check for necessary and sufficient conditions for whether the tax reform can be considered to be unambiguously pro-poor. Although simple to test for, the pro-poorness of a tax reform can nevertheless differ quite significantly from the optimal taxation literature's results on whether a tax reform improves social welfare.

For instance, a revenue-neutral tax reform that does not change the aggregate deadweight loss (it is therefore efficiency neutral) and that increases the price of good $j$ but decreases the price of good $i$ is absolutely and relatively pro-poor if the poor's (weighted) share of the total consumption of good $i$ exceeds their (weighted) share of the total consumption of good $j$ - the shares being given by the poor's poverty gaps. If, however, real income falls after the tax reform (because of a rise in the total deadweight loss, relative pro-poorness demands that the share of the poor in total real income does not fall after the reform, but absolute pro-poorness demands that the absolute real income of the poor does not fall after the reform by more than the absolute fall in average real income. An economically inefficient reform will therefore be more likely to be absolutely pro-poor than relatively pro-poor. 
The more inefficient it is to tax a good, or the more price elastic is a good, the greater the tax rate that must be levied on that good to generate the tax revenues needed to decrease taxes on another good. If the more price-elastic good is not a luxury good, this makes increasing its price less likely to be relatively pro-poor. Only when the price-elastic good is also a luxury good will an increase in its tax be conducive to greater relative pro-poorness. An efficiency-decreasing tax reform will also be more likely to be considered relatively pro-poor than absolutely propoor as the importance given to the poorest of the poor increases.

Section 3 then proceeds by proposing estimators and deriving sampling distributions for the tools needed to test for tax pro-poorness. This is needed to implement the analytical methods using survey data. For the important case of first-order pro-poorness, these estimators involve non-parametric regressions, for which the sampling distributions that need to be derived are more involved. The estimators and their sampling distributions cover all of the possible analytical cases derived in Section 2.

Section 4 applies the methodology to Mexico's indirect tax system using Mexico's 2004 ENIGH database. We find for instance that a marginal tax reduction on Food or on Energy would be relatively pro-poor, and that this conclusion would be valid for a very large class of relative pro-poor judgements. But, according to the paper's definition of absolute pro-poorness, a marginal reduction in taxes on any of the different goods considered would need to be thought of as being absolutely anti-poor. A revenue- and efficiency-neutral tax reform that decreases Food taxes and increases Transportation taxes would be considered absolutely and relatively pro-poor for all indices and lines within a wide class and range. The application also shows that applying statistical inference techniques can alter conclusions in a way that sometimes contrasts importantly with the analysis made solely on the basis of sample estimates.

The paper is a natural and significant extension of some of the work that we have carried out in the recent years. ${ }^{7}$ The current paper uses and adapts the consumption-dominance curves introduced in Makdissi and Wodon (2002) to analyze both absolute and relative pro-poorness of tax reforms, and this, in a framework that allows for absolute pro-poorness to differ from the usual objectives of absolute poverty reduction — see for instance Definition 2 on page 10. As in

\footnotetext{
${ }^{7}$ It is also a much revised version of a paper presented at a symposium held in Monterrey in October 2007; see Audet, Makdissi, Araar, and Duclos (2007) for a preliminary version that appeared in the Symposium proceedings. The current paper expands on the theoretical framework, explores the links between efficiency and pro-poorness, and also presents statistical inference techniques that are then applied to Mexican data.
} 
Araar, Duclos, Audet, and Makdissi (2009) for testing growth pro-poorness, the current paper provides statistical inference methods for testing pro-poorness, but the methods developed in this paper are more involved since they deal with the impacts of marginal price changes and since they must thus take into account the joint distribution of total and specific commodity consumption levels. The statistical methods developed in this paper also differ markedly for first- and higherorders of pro-poorness. The current paper also develops measurement and statistical methods that help address the difficult trade-off between efficiency and distribution. It also examines why the usual search for efficient tax reforms may not be justified in the presence of concerns for relative policy pro-poorness and for inequality alleviation.

Section 5 concludes by summarizing briefly the main results. Most of the proofs of the main results can be found in the Appendix of Section 6.

\section{Notation and methodological framework}

\subsection{Poverty Measurement}

We first start with the presentation of rather general views of how poverty and tax pro-poorness can be assessed. For simplicity, suppose that poverty indices are additive $^{8}$ and therefore take the form of

$$
P(z)=\int_{-\infty}^{\infty} p(y, z) d F(y)
$$

where $y$ is real income, $z$ is the poverty line (in real terms), $F(\cdot)$ is the cumulative distribution function of income, and $p(y, z)$ is a function that measures the poverty of an individual with an income $y$ and using a poverty line $z$. It is useful here to think of both $y$ and $z$ as defined with respect to constant reference prices - or as "real" variables. Defining the poverty line in the real income space rather than in the nominal income space is convenient since the poverty line is then invariant to tax reforms. In this paper, and as discussed below in Section 2.2, we also suppose that pre-reform nominal and real incomes are the same since we set reference prices to pre-reform prices. ${ }^{9}$

\footnotetext{
${ }^{8}$ The Foster, Greer, and Thorbecke (1984) indices are an example of popular additive poverty measures. Other examples of additive indices can be found in Watts (1968), Clark, Hemming, and Ulph (1981) and Chakravarty (1983).

${ }^{9}$ This is the common — though arbitrarily-made — assumption in the literature; see Donaldson (1992) for a general discussion.
} 
We suppose that $p(y, z) \geq 0$ and that $p(y, z)=0$ for all $y>z$. Duclos and Makdissi (2004) use the properties of $P(z)$ to define classes of poverty indices $\Pi^{s}(z)$ for some order $s$. These classes are defined by:

$$
\Pi^{s}(z)=\left\{\begin{array}{c|c}
p(y, z) \in \widehat{C}^{s}(z), \\
P(z) \mid \begin{array}{c}
i \\
(-1)^{i} p^{(i)}(y, z) \geq 0 \text { for } i=0,1,2, \ldots, s, \\
p^{(t)}(z, z)=0 \text { for } t=0,1,2, \ldots, s,
\end{array}
\end{array}\right\}
$$

where $p^{(i)}(y, z)$ represents the $i$-th derivative of $p(y, z)$ with respect to $y$ and $\widehat{C}^{s}$ is the set of continuous functions that are $s$-times differentiable on $[0, \omega]$.

For poverty indices $P \in \Pi^{1}(z)$, an increase in the income of any one individual will weakly reduce the poverty index. This class of indices is thus Paretian. The indices are also symmetrical since exchanging incomes between two individuals will not affect poverty (by the property of the anonymous distribution function in (1)). This type of indices can thus be said to satisfy Pen (1971)'s principles for comparing distributions (see Duclos, Makdissi, and Wodon 2008).

The poverty indices included in $\Pi^{2}(z)$ are also convex. This implies that they respect the Pigou-Dalton principle of transfer, a principle that states that a transfer from any one individual to a poorer individual should weakly decrease poverty. In addition to obeying the above principles, the poverty indices that belong to $\Pi^{3}(z)$ must also obey the Kolm (1976) principle of transfers, which states that a PigouDalton transfer that takes place at the bottom of the distribution should have a greater impact on poverty than one taking place higher up in the distribution. Hence, a progressive transfer that occurs within a lower part of the distribution will reduce poverty even if it is accompanied by a symmetric regressive transfer higher up in the distribution. Indices of a class $\Pi^{s}(z)$ with $s$ greater then 3 can be interpreted by using the generalized transfer principle proposed by Fishburn and Willig (1984). This generalized principle states that the greater the order $s$, the greater is the sensibility of an index to changes occurring in a lower part of the distribution.

\subsection{Impact of price changes}

Let us now suppose that we wish to test whether an indirect tax reform can be considered to be pro-poor. We consider three possible scenarios through which this can be done.

1. The government wishes to implement a marginal reduction in the tax (or a marginal increase in the subsidy) on good $i$, without attempting to offset 
the fall in total government revenue (possibly because the government is running a budget surplus).

2. The government wishes to implement a marginal increase in the tax (or a marginal decrease in the subsidy) on good $i$, without attempting to offset the increase in total government revenue (possibly because the government is running a budget deficit).

3. The government wishes to implement a revenue-neutral indirect tax reform. It must therefore finance a marginal tax reduction on good $i$ (or a marginal increase in its subsidy) with a marginal increase in the tax (or a marginal decrease in the subsidy) on $\operatorname{good} j \neq i$.

Now assume that producer prices are held constant and, for expositional simplicity, set them to 1 , so that $q=e+t$, where $q$ is the vector of current consumption prices, $e$ is a vector of ones, and $t$ is the vector of indirect taxes. Let $\iota$ be nominal income (which could be full income, including the value of leisure if we were to model labor income taxation). The indirect utility function is given by $v(\iota, q)$. Following King (1983), we use a vector of reference prices, $q^{R}$, to assess welfare in the presence of varying tax rates. Denote the real (or equivalent) income in the post-reform situation by $y$, where $y$ is measured on the basis of the reference prices $q^{R}$. $y$ is implicitly defined by $v\left(y, q^{R}\right)=v(\iota, q)$, and explicitly by the real income function $y=\rho\left(\iota, q, q^{R}\right)$, where

$$
v\left(\rho\left(\iota, q, q^{R}\right), q^{R}\right) \equiv v(\iota, q) .
$$

By definition, $y=\rho\left(\iota, q, q^{R}\right)$ gives the level of income that provides under $q^{R}$ the same utility as $\iota$ yields under $q$.

We then wish to determine how welfare is affected by a marginal change in tax rates. Let $x_{i}(\iota, q)$ be the consumption of good $i$ of a consumer with income $\iota$ and facing prices $q$. Using Roy's identity and setting reference prices to pre-reform prices, we find:

$$
\left.\frac{\partial y}{\partial t_{i}}\right|_{q=q^{R}}=\left.\frac{\partial \rho\left(\iota, q, q^{R}\right)}{\partial t_{i}}\right|_{q=q^{R}}=-x_{i}\left(\iota, q^{R}\right) .
$$

Equation (4) says that the observed pre-reform consumption of good $i$ is a sufficient statistic to know the impact on consumer welfare of a marginal change in the price of good $i$. Note that (4) is valid for rationed goods too. Note also that 
$x_{i}\left(\iota, q^{R}\right)$ is the uncompensated demand; this may seem to differ from the standard Ramsey analysis of optimal taxation in which compensated demands play a crucial role, but here the use of the two demands is equivalent since $q^{R}=q$.

With $q$ initially equal to $q^{R}$, a marginal change to the tax on a good $i$ will impact an individual's poverty level $p(y, z)$ by

$$
\frac{\partial p(y, z)}{\partial t_{i}}=p^{(1)}(y, z) \frac{\partial y}{\partial t_{i}}=-p^{(1)}(y, z) x_{i}(\iota, q)=-p^{(1)}(y, z) x_{i}(y, q) .
$$

\subsection{Pro-poorness}

We do not wish, however, to determine if a tax reform reduces or increases poverty, but rather if it can be considered to be pro-poor. This requires distinguishing between relative and absolute pro-poorness. We will say that a tax reform is $R$-pro-poor for relative pro-poorness and $A$-pro-poor for absolute propoorness. In the growth terminology of Duclos (2009) and Araar, Duclos, Audet, and Makdissi (2007), relative pro-poorness is checked by comparing $P(z)$ using $F_{1}((1+g) y)$ for a posterior distribution $F_{1}(y)$ to $P(z)$ using an initial distribution $F_{0}(y)$, using a relative "norm" $g$ (to be discussed later). The posterior distribution $F_{1}((1+g) y)$ is the distribution of actual posterior incomes when those incomes are divided by $(1+g)$. Absolute pro-poorness with an absolute norm $a$ (also discussed below) is checked by comparing $P(z)$ using $F_{1}(y+a)$ for a posterior distribution $F_{1}(y)$ to $P(z)$ using an initial distribution $F_{0}(y)$. The distribution $F_{1}(y+a)$ is the distribution of actual posterior incomes minus $a$.

From (1) and performing a change of variables, we can formally define relative and absolute pro-poorness as:

Definition 1 A movement from an initial distribution $F_{0}$ to a posterior distribution $F_{1}$ is judged relatively pro-poor by an index $P(z)$ if and only if

$$
\int_{-\infty}^{\infty} p\left(\frac{y}{1+g}, z\right) d F_{1}(y)-\int_{-\infty}^{\infty} p(y, z) d F_{0}(y)<0 .
$$

Definition 2 A movement from an initial distribution $F_{0}$ to a posterior distribution $F_{1}$ is judged absolutely pro-poor by an index $P(z)$ if and only if

$$
\int_{-\infty}^{\infty} p(y-a, z) d F_{1}(y)-\int_{-\infty}^{\infty} p(y, z) d F_{0}(y)<0 .
$$


These two definitions demonstrate again the difference between relative and absolute pro-poorness. Relative pro-poorness normalizes incomes by a ratio $1+g$, whereas absolute pro-poorness uses the spread of incomes from a standard $a$. For expositional simplicity, we will assume for the purposes of this paper that the relative norm $g$ is set to the growth rate of average real income. This is consistent with the view of Kakwani and Pernia (2000) (p.3) that "promoting pro-poor growth requires a strategy that is deliberately biased in favor of the poor so that the poor benefit proportionately more than the rich." It is also consistent with the view that relative pro-poorness is tightly linked to inclusiveness and participation of the poor in growth processes and (more generally) in distributional changes. Setting $g$ to the growth rate of average real income also allows linking relative pro-poorness to relative inequality reduction, as we will discuss more explicitly later.

Again for expositional simplicity, the absolute norm $a$ is set in this paper to the numerical (as distinct from the proportional) change in average real income. Loosely speaking, this implicitly supposes that we wish distances between incomes and the mean not to be increased by distributional changes. This also implicitly links absolute pro-poorness to absolute inequality reduction. Along that view, a tax reform that decreases mean income because it increases government revenue could still be considered absolutely pro-poor, possibly because the increase in government revenue would allocate to everyone an increase in the absolute value of public goods equal to the increase in average government revenue. Generalizations of this to other settings would not be difficult, by setting for instance $g$ to growth in some quantiles (such as the median), or by setting $a$ to 0 (which would be equivalent to arguing that a change is pro-poor if it decreases absolute poverty - e.g., Ravallion and Chen 2003).

\subsection{The impact of single price changes}

We now turn to the effects of tax reforms on $g$ and $a$. Let $\mu=\int y d F(y)$ be average income. The average impact of $d t_{i}$ on real income in the total population is given by $d t_{i}$ times the average consumption of good $i$, which is denoted as $X_{i}(q)$ :

$$
X_{i}(q)=\int_{-\infty}^{\infty} x_{i}(y, q) d F(y) .
$$

A marginal change $d t_{i}$ thus induces a proportional change in average real income equal to

$$
g=\frac{\partial \mu / \partial t_{i}}{\mu} d t_{i}=-\frac{X_{i}(q)}{\mu} d t_{i}
$$


and an absolute change in average real income given by

$$
a=\frac{\partial \mu}{\partial t_{i}} d t_{i}=-X_{i}(q) d t_{i}
$$

Using (4), we then have

$$
\left.\frac{\partial(y /(1-g))}{\partial t_{i}}\right|_{g=0} d t_{i}=\left[-x_{i}(y, q)+y \frac{X_{i}(q)}{\mu}\right] d t_{i}
$$

and

$$
\left.\frac{\partial(y-a)}{\partial t_{i}}\right|_{a=0} d t_{i}=\left[-x_{i}(y, q)+X_{i}(q)\right] d t_{i}
$$

\subsection{Testing for pro-poorness of single price changes}

We now introduce pro-poor consumption dominance curves $\left(C D^{\eta: s}\right), \eta \in$ $\{A, R\}$ and $s \in\{1,2,3 \ldots\} .{ }^{10}$ Those pro-poor consumption dominance curves are defined as:

$$
C D_{i}^{R: s}(z)=\left\{\begin{array}{cc}
{\left[\frac{x_{i}(z, q)}{X_{i}(q)}-\frac{z}{\mu}\right] f(z)} & \text { for } s=1 \\
\int_{-\infty}^{z} C D_{i}^{R: s-1}(y) d y & \text { for } s \geq 2
\end{array}\right.
$$

and

$$
C D_{i}^{A: s}(z)= \begin{cases}{\left[\frac{x_{i}(z, q)}{X_{i}(q)}-1\right] f(z)} & \text { for } s=1 \\ \int_{-\infty}^{z} C D_{i}^{A: s-1}(y) d y & \text { for } s \geq 2 .\end{cases}
$$

By integration by parts, (13) and (14) can be written for $s=2,3, \ldots$ as

$$
C D_{i}^{R: s}(z)=\frac{1}{(s-2) !} \int_{-\infty}^{z}\left[\frac{x_{i}(y, q)}{X_{i}(q)}-\frac{y}{\mu}\right](z-y)^{s-2} d F(y)
$$

and

$$
C D_{i}^{A: s}(z)=\frac{1}{(s-2) !} \int_{-\infty}^{z}\left[\frac{x_{i}(y, q)}{X_{i}(q)}-1\right](z-y)^{s-2} d F(y) .
$$

\footnotetext{
${ }^{10}$ Consumption dominance curves were introduced in Makdissi and Wodon (2002).
} 
It can be seen from (15) and (16) that the $C D_{i}^{\eta: s}$ curves integrate the impacts of price changes on real incomes, normalized by the average impact $X_{i}(q)$ and by changes $g$ and $a$ in the "pro-poor norms". These impacts are weighted by gaps between $z$ and $y$ to a power $s-2$. This leads to our first main analytical result.

Theorem 1 A marginal decrease in the tax on good $i$ is $\eta$-pro-poor $(\eta \in\{A, R\})$ for all indices $P(z) \in \Pi^{s}(z)$ and for all poverty lines $z \in\left[0, z^{+}\right]$if and only if

$$
C D_{i}^{\eta: s}(z) \geq 0, \forall z \in\left[0, z^{+}\right] .
$$

It is useful to interpret Theorem 1 in the context of the first two scenarios listed at the beginning of Section 2.2 on page 8 . For this, let us first classify goods according to their income elasticity, $\varepsilon_{i}^{y}$.

Definition 3 A good $i$ is said to be an inferior good if $\varepsilon_{i}^{y}<0$ and a normal good if $\varepsilon_{i}^{y}>0$, for all $y$.

Definition 4 A normal good is said to be a necessary good if $\varepsilon_{i}^{y}<1$ and a luxury good if $\varepsilon_{i}^{y}>1$, for all $y$.

Four simple remarks can then be made as a corollary to Theorem 1.

Corollary 1 Regardless of the value of $s$ and $z^{+}$:

1. a reduction (an increase) in the tax of good $i$ is never (always) A-pro-poor if the good is a normal good;

2. a reduction (an increase) in the tax of good $i$ is always (never) A-pro-poor if the good is an inferior good;

3. a reduction (an increase) in the tax of good $i$ is never (always) $R$-pro-poor if the good is a luxury good;

4. a reduction (an increase) in the tax of good $i$ is always (never) $R$-pro-poor if the good is a necessity.

For goods to be normal, inferior, luxury or necessity goods, the income elasticities have to be everywhere negative, positive, or below or above 1 for all values of $y$. The income elasticities $\varepsilon_{i}^{y}$ do not of course have to be uniformly negative, positive, or below or above 1 for all values of $y$. When elasticities are not so uniformly distributed, condition (17) will have to be checked on a case-by-case distributional basis using Theorem 1 . 


\subsection{Testing for pro-poorness of tax reforms}

The above results are useful only in the cases in which only one tax or one price is changed, if for instance the government does not necessarily want to keep its overall revenue unchanged. For the case of a revenue-neutral tax reform scenario, one must finance a marginal tax reduction for a good $i$ by a marginal increase in the tax on a good $j$ in order to keep overall tax revenue constant. To show how to do this, suppose that there are $K$ consumption goods and denote by $T$ the per capita tax revenue of the overall indirect tax system:

$$
T(q)=\sum_{k=1}^{K} t_{k} X_{k}(q)
$$

The impact of the marginal tax reform on per capita tax revenue is then given by $d T$ :

$$
d T=\left[X_{i}(q)+\sum_{k=1}^{K} t_{k} \frac{\partial X_{k}(q)}{\partial t_{i}}\right] d t_{i}+\left[X_{j}(q)+\sum_{k=1}^{K} t_{k} \frac{\partial X_{k}(q)}{\partial t_{j}}\right] d t_{j} .
$$

Revenue neutrality implies that $d T=0$. Using (19), this leads to:

$$
d t_{j}=-\gamma_{i, j}\left(\frac{X_{i}(q)}{X_{j}(q)}\right) d t_{i} \text { where } \gamma_{i, j}=\frac{1+\frac{1}{X_{i}(q)} \sum_{k=1}^{K} t_{k} \frac{\partial X_{k}(q)}{\partial t_{i}}}{1+\frac{1}{X_{j}(q)} \sum_{k=1}^{K} t_{k} \frac{\partial X_{k}(q)}{\partial t_{j}}} .
$$

Wildasin (1984) describes $\gamma_{i, j}$ as the efficiency cost ratio of obtaining one dollar of public funds by taxing good $j$ to subsidize good $i$. (In what follows, we will often drop the ${ }_{i, j}$ from $\gamma_{i, j}$ for expositional simplicity.) We can now state our second main result.

Theorem 2 A marginal tax reduction on good $i$ financed by a marginal increase in the tax on good $j$ is $\eta$-pro-poor $(\eta \in\{A, R\})$ for all indices $P(z) \in \Pi^{s}(z)$ and for all poverty lines $z \in\left[0, z^{+}\right]$if and only if

$$
C D_{i}^{\eta: s}(z)-\gamma C D_{j}^{\eta: s}(z) \geq 0, \forall z \in\left[0, z^{+}\right] .
$$

The proof follows directly from that of Theorem 1. 


\subsection{Discussion}

\section{Efficiency and dominance}

Yitzhaki and Thirsk (1990) and Yitzhaki and Slemrod (1991) find that if $\gamma$ is superior to one, it is impossible to secure a second-order welfare dominant tax reform due to the efficiency loss incurred. From a poverty perspective, Makdissi and Wodon (2002) note, however, that it is possible to have a reform that is poverty dominant at all orders of stochastic dominance even when $\gamma$ is greater than one, so long as that part of the burden is supported by the non poor. This result also applies in this context of pro-poor tax reforms. The main difference between Theorem 2 and the stochastic dominance condition in Makdissi and Wodon (2002) lies in the mathematical formulation of the $C D_{i}^{\eta: s}$ curves. This difference is important if we want to test for pro-poorness of a reform, a condition that is more demanding than in the poverty reduction framework of Makdissi and Wodon (2002). In the context of $R$ and $A$ pro-poorness, it is indeed the weighted difference between $C D_{i}^{\eta: s}(y)-\gamma C D_{j}^{\eta: s}(y)$ that matters. A tax reform can be economically inefficient (with $\gamma>1$ ) and still be considered to be pro-poor if $C D_{j}^{\eta: s}(y)$ is not too large.

\section{Pro-poorness and inequality}

Theorems 1 and 2 can also be used to assess the impact of price changes and tax reforms on absolute and relative inequality for any given order of dominance. This is because of the specification of $a$ and $g$ chosen in this paper. In (6) for relative pro-poorness, post-reform incomes are normalized by the ratio of average real incomes. This essentially serves to equalize average real incomes across the pre- and the post-reform distributions. Using Duclos and Makdissi (2004), the conditions (2) on the class of evaluation functions then make it possible to use Theorems 1 and 2 to provide unambiguous conclusions on the impact of price changes and tax reforms on relative inequality.

For absolute pro-poorness, (7) essentially centers real incomes around their respective mean value. That makes it possible to use Theorems 1 and 2 to provide unambiguous conclusions on the impact of price changes and tax reforms on absolute inequality - that is, on inequality indices that aggregate distances between incomes and their mean value in a way that is consistent with the conditions defined in (2). 


\section{The role of consumption shares}

When $s=1$ and when $\gamma=1$ (when there is no efficiency benefit or cost to the tax reform), Theorem 2 says that a tax reform is absolutely pro-poor if the poor's share of the total consumption of good $i$ exceeds their share of the total consumption of good $j$. Exactly the same interpretation applies to the relative propoorness of a tax reform when $\gamma=1$ : the poor's share of the total consumption of good $i$ must exceed their share of the total consumption of good $j$. This is because mean real income is unaffected by a revenue-neutral tax reform when $\gamma=1 .^{11}$

\section{Efficiency-changing reforms}

When $\gamma \neq 1$, the interpretation of $A$ and $R$ pro-poorness differs. Take $\gamma>1$, a case in which average real income falls after the tax reform (because of the efficiency cost). This is analogous to a case of negative growth. Relative propoorness demands that the share of the poor in total real income does not fall after the reform. Absolute pro-poorness demands that the absolute real income of the poor does not fall after the reform by more than the absolute fall in total real income. Since the initial share of the poor in total income is less than one $(y / \mu$ is less than one in (15)), an economically inefficient reform will be more likely to be absolutely pro-poor than relatively pro-poor.

The reverse reasoning applies to the case of an economically efficient tax reform, for which $\gamma<1$ and average real income increases. Relative pro-poorness demands that the share of the poor in total real income increases after the reform, and absolute pro-poorness will require that the absolute real income of the poor increases by more than total real income after the reform. Because of this, an economically efficient reform will be more likely to be relatively pro-poor than absolutely pro-poor.

If $\gamma<1$, a reform will also be more likely to be considered relatively propoor than absolutely pro-poor as $s$ increases. The converse holds if $\gamma>1$. This is because the greater the value of $s$, the greater the importance given to the poorest of the poor in assessing pro-poorness conditions. (13) and (14) show that the standard in assessing relative pro-poorness is the difference between shares in the consumption of a good and shares in total income, but that the standard in assessing absolute pro-poorness is the difference between shares in the consumption of a good and 1. For the poor, that difference for relative pro-poorness will be larger than for absolute pro-poorness. Since an increase in $s$ increases the importance

\footnotetext{
${ }^{11}$ When $\gamma=1$, we have $g=a=0$ since $X_{j} d t_{j}+X_{i} d t_{i}=0$.
} 
given to the poorer individuals, ceteris paribus, an increase in $s$ will also lead more quickly to the validation of (21) for $\eta=R$ than for $\eta=A$ if $\gamma<1$, and more quickly to the validation of (21) for $\eta=A$ than for $\eta=R$ if $\gamma>1$. If $\gamma=1$ this difference vanishes as the conditions for relative or absolute pro-poorness of tax reforms become both equivalent to the condition that a tax reform reduces poverty (see Duclos, Makdissi, and Wodon 2008).

\section{Estimation and inference}

To be able to implement empirically the above tools, we ought to consider the estimation and the sampling distribution of the curves needed to test for propoorness. For this, we suppose for expositional simplicity that we dispose of a sample of $N$ independently and identically distributed observations, ${ }^{12}$ and that the pre-reform income and consumption of goods $j$ and $l$ for observation $i$ ( $i=$ $1, \ldots, N)$ are denoted by $y_{i}, x_{j}^{i}$ and $x_{l}^{i}$, respectively. Ignoring the constant $\frac{1}{(s-2) !}$, the $C D^{\eta: s}$ curves can then be estimated for $s \geq 2$ by the natural estimators

$$
\widehat{C D}_{k}^{R: s}(z)=\frac{\frac{1}{N} \sum_{i=1}^{N} x_{k}^{i}\left(z-y_{i}\right)_{+}^{s-2}}{\widehat{X}_{k}}-\frac{\frac{1}{N} \sum_{i=1}^{N} y_{i}\left(z-y_{i}\right)_{+}^{s-2}}{\widehat{\mu}}
$$

and

$$
\widehat{C D}_{k}^{A: s}(z)=\frac{\frac{1}{N} \sum_{i=1}^{N} x_{k}^{i}\left(z-y_{i}\right)_{+}^{s-2}}{\widehat{X}_{k}}-\frac{1}{N} \sum_{i=1}^{N}\left(z-y_{i}\right)_{+}^{s-2},
$$

where $f_{+}=\max (0, f), \widehat{X}_{k}=\frac{1}{N} \sum_{i=1}^{N} x_{k}^{i}$ is an estimator of average consumption of good $k$, and $\widehat{\mu}=\frac{1}{N} \sum_{i=1}^{N} y^{i}$ is an estimator of average income.

The estimators $\widehat{C D}_{l} \eta: s(z)-\gamma \widehat{C D}_{j}^{\eta: s}(z)$ are given analogously. Let $C D^{s}\left(x_{k} ; z\right)=$ $\int_{-\infty}^{z} x_{k}(y, q)(z-y)^{s-2} d F(y)$ and $\widehat{C D}^{s}\left(x_{k} ; z\right)=\frac{1}{N} \sum_{i=1}^{N} x_{k}^{i}\left(z-y_{i}\right)_{+}^{s-2}$. The asymptotic sampling distribution of $\widehat{C D}^{s}\left(x_{k} ; z\right)$ for $s \geq 2$ is given in Theorem 3 .

\footnotetext{
${ }^{12}$ The analytical results can be extended to account for complex multi-stage sampling designs. Taking into account sampling design is indeed done in the Mexican illustration below, using analytical asymptotic methods along the lines of those described in Duclos and Araar (2006), Chapter 16. More details can be obtained from the authors upon request.
} 
Theorem 3 Let the second population moment of $x_{k}(y, \theta)(z-y)_{+}^{s-2}$ be finite. Then, for $s \geq 2, N^{0.5}\left(\widehat{C D}^{s}\left(x_{k} ; z\right)-C D^{s}\left(x_{k} ; z\right)\right)$ is asymptotically normal with mean zero and with asymptotic variance given by:

$$
\begin{aligned}
& \lim _{N \rightarrow \infty} N \cdot \operatorname{var}\left(\widehat{C D}^{s}\left(x_{k} ; z\right)-C D^{s}\left(x_{k} ; z\right)\right) \\
= & (s-2) !^{-2} \int\left(x_{k}(y)(z-y)_{+}^{s-2}\right)^{2} d F(y)-C D^{s}\left(x_{k} ; z\right)^{2} .
\end{aligned}
$$

Prof: See the appendix.

The asymptotic distribution of $\widehat{C D}_{k}^{R: s}(z)$ and $\widehat{C D}_{k}^{A: s}(z)$ can be obtained by noting that (22) and (23) are functions of $\widehat{C D}^{s}\left(x_{k} ; z\right), \widehat{X}_{k}, \widehat{C D}^{s}(y ; z), \widehat{\mu}$, and $\widehat{C D}^{s}(1 ; z)$. The sampling distributions $\widehat{C D}^{s}(y ; z)$ and $\widehat{C D}^{s}(1 ; z)$ can be obtained as special cases of Theorem 3. $\widehat{\mu}$ and $\widehat{X}_{k}$ are simple sums of independently and identically distributed random variables. Using the "delta method" of Rao (1973), the sampling distribution of $\widehat{C D}_{k}^{A: s}(z)$ and $\widehat{C D}_{k}^{R: s}(z)$ can then be obtained by a linear transformation of the covariance matrix of $\widehat{C D}^{s}\left(x_{k} ; z\right), \widehat{X}_{k}, \widehat{C D}^{s}(y ; z), \widehat{\mu}$, and $\widehat{C D}^{s}(1 ; z)$.

For $s=1$, we need an estimator of $x_{k}(z, q)$, the expected consumption of good $k$ at $z$, times $f(z)$. For this, we can use a non-parametric estimation procedure, using for instance a kernel estimator defined such as

$$
\widehat{C D}^{1}\left(x_{k} ; z\right)=\frac{1}{N} \sum_{i=1}^{N} \kappa_{h}\left(z-y_{i}\right) x_{k}^{i},
$$

where $h$ is a kernel bandwidth, $\kappa_{h}(u)=h^{-1} \kappa(u / h), \int \kappa(u) d u=1, \int u \kappa(u) d u=$ 0 (for symmetry), and $\int u^{2} \kappa(u) d u=c_{\kappa}$. In the illustration below, we choose a Gaussian form for $\kappa(u)$,

$$
\kappa(u)=\frac{e^{-0.5 u^{2}}}{\sqrt{2 \pi}},
$$

but other kernel functional forms could also be used. In the illustration, we choose $h$ using the cross-validation method, which is asymptotically optimal (see Härdle 1990, Theorem 5.1.1), and we also use a locally linear estimator to avoid biases at the lower bound of expenditures. Theorem 4 then gives the asymptotic sampling distribution of $\widehat{C D}^{1}\left(x_{k} ; z\right)$. 
Theorem 4 Let i) $\int \kappa(u)^{2} d u$ exists, ii) $h \sim N^{-0.2}$, iii) $C D_{k}^{1}(y)$ be twice differentiable in $y$ at $y=z$, iv) $f(z)>0$, and v) $c_{k}(z)=x_{k}(z)^{2}$ be continuous at $z$. Then, $(N h)^{0.5}\left(\widehat{C D}^{1}\left(x_{k} ; z\right)-C D^{1}\left(x_{k} ; z\right)-h^{2} B_{k}(z)\right)$ is asymptotically normal with mean 0 and limiting variance $V_{k}(z)$, where $B_{k}(z)=0.5 c_{\kappa} \partial^{2} C D^{1}\left(x_{k} ; z\right) /(\partial z)^{2}$ and $V_{k}(z)=f(z) c_{k}(z) \int \kappa(u)^{2} d u$.

Prof: See the appendix.

The sampling distribution of $\widehat{C D}_{k}^{R: 1}(z)$ and $\widehat{C D}_{k}^{A: 1}(z)$ can then be obtained by a linear transformation of the covariance matrix of $\widehat{C D}^{1}\left(x_{k} ; z\right), \widehat{X}_{k}$ and $\widehat{\mu}$ using the delta method. As for $s \geq 2$, the terms needed to carry out statistical inference are either constants $\left(c_{\kappa}\right.$ and $\left.\int \kappa(u)^{2} d u\right)$ or can be readily estimated consistently in a distribution-free manner (this is the case, for instance, of $\int\left(x_{k}(z-y)_{+}^{s-2}\right)^{2} d F(y), \widehat{C D}^{s}\left(x_{k} ; z\right)^{2}, \partial^{2} C D^{1}\left(x_{k} ; z\right) /(\partial z)^{2}, f(z)$ and $\left.c_{k}(z)\right)$. Note, however, that it is usual to consider (and to find) the bias terms $B_{k}(z)$ and $B_{k}(z) / X_{k}$ to be of negligible practical importance ${ }^{13}$, and we also make this assumption in the illustration below.

\section{An application to Mexico's indirect tax system}

\subsection{Mexican data}

We now briefly apply the above methodology to Mexico's indirect tax system. The data used for our application comes from the 2004 National Income and Expenditure (ENIGH) Survey, whose 22,595 observations are nationally representative of the Mexican population. ENIGH surveys collect information on incomes and various expenditure items, goods and services used for self-consumption, as well as socio-economic characteristics and labor market activities of all household members.

As is common in Latin America, we use total income per capita as the measure of living standards for all members of a household. To correct for spatial variation in prices, we express all incomes in units of rural prices by multiplying urban household incomes by the ratio of rural to urban poverty lines. Mexico's Ministry of Social Development estimates the food poverty line as the income

\footnotetext{
${ }^{13}$ This is particularly true in the study of consumption data, where the second order derivative of expected consumption at $z, \partial^{2} C D^{1}\left(x_{k} ; z\right) /(\partial z)^{2}$, may be expected to be small. For more on this, see for instance Härdle (1990), p.101.
} 
required to purchase a food basket that is sufficient to satisfy some minimal nutritional requirements. This food basket is estimated separately for rural and urban areas, and is based upon the food consumption of those households that just meet the minimal nutrient requirements. The non-food poverty line is estimated by averaging the non-food shares in total consumption of the 10-percent of households whose food expenditures are closest to the food poverty line. This provides the average non-food component of the total poverty line. Expressed in 2000 prices, the total rural poverty line is then estimated to be approximately 550 pesos per month per capita. ${ }^{14}$

To simplify the interpretation of figures and the discussion, we normalize income by that rural poverty line so that a household with an income equal to one is at the level of the rural poverty line and a household with an income of 2 has a real income equal to twice that line. We weight households by the product of household size and household sampling weight; this is equivalent to formulating our estimators on the basis of the population of individual living standards.

Tax revenue in Mexico mostly comes from the income tax, the value-added tax (VAT), and local levies on real property. The federal government also imposes excise taxes on alcohol and cigarettes as well as production taxes on mining. The main indirect tax is Mexico's value-added tax (VAT). Since 1980, Mexico's standard VAT rate is $15 \%$ on most goods and services, except in border zones where it is $10 \%$. Health and food products are zero-rated. VAT-exempt goods and services include animals, vegetables, and fruits other than for industrial use; tractors, fertilizers, and pesticides; rentals of agricultural machinery; international freight; international air passenger service, pre-paid cellular phone service, radio paging and beeper services, natural gas for car fuel, and imports and exports in specific warehouse facilities. A 5\% luxury tax on luxury cars, jet skis, salmon, golf, horseback riding, was abolished in 2003. Though the tax reforms of 2001 give the states leeway to impose sales taxes up to $3 \%$, none has done so. With effect from 1 January 2010, standard VAT rates in Mexico have increased by $1 \%$.

We consider indirect tax reforms affecting four broad classes of goods and services (food, energy, transport and other goods) as well as various foodstuffs. ${ }^{15}$ Table 1 presents the total expenditure shares of the consumption of different goods and services, by quintile. ${ }^{16}$ As expected, the share of total expenditures on food

\footnotetext{
${ }^{14}$ For more details, see World Bank (2004).

${ }^{15}$ In 2004, all foodstuffs were exempt of value-added taxes (VAT) in Mexico. A few of these goods were subsidized, however.

${ }^{16}$ See also Navajas and Porto (1994) for a nice discussion of why it is the evolution of these shares across quantiles - and not the level differences of these shares across goods and services
} 
items decreases from the poorest to the richest quintile. Conversely, the share of total expenditures on transportation and other goods increases with quantiles. Table 1 also shows that the composition of the food basket varies with income quantiles; households in the poorest income quintile spend a greater share of their total food expenditure on cereals $(25.88 \%)$ and on vegetables $(19.30 \%)$ than those in the richest quintile - who spend relatively more (46.44\%) on protein-intensive foods (milk, meat and fish).

\subsection{Impact of tax changes}

Figure 1 presents relative dominance curves $C D^{R: s}(z)$ for three broad classes of goods and services and for $s=1,2$, along with two-sided $90 \%$ confidence intervals. Using the results of Theorem 1, this shows that a marginal tax reduction on Food or on Energy would be relatively pro-poor, and that this conclusion would be valid for any relative pro-poor judgements based on indices $P \in \Pi^{1}(z)$ (namely, those that are in agreement with the Pen principle) for a wide range of poverty lines reaching almost 3 . For $s=2$, this is true for all possible poverty lines. Conversely, a marginal increase in the tax on any of these two classes of goods would be considered relatively "anti-poor". This suggests that it is important to consider the use to which increases in tax revenues are put to know whether a tax reform is globally pro-poor or not, since tax reforms generate changes in more than one price. We return to this below.

Figure 2 presents the corresponding absolute dominance curves $C D^{A: s}(z)$ for three broad classes of goods and services. A marginal reduction in taxes on any of the different goods could not be considered to be absolutely pro-poor. As indicated in Corollary 1, this result is not surprising considering the fact that the absolute pro-poor requirements are typically more demanding (since most goods are normal goods) than the relative ones (since not all normal goods are luxury goods) in the case of tax decreases. Conversely, increases in taxes on any of the different goods will be absolutely pro-poor for all $P \in \Pi^{1}(z)$ for a large range of poverty lines and for all $P \in \Pi^{2}(z)$ for all poverty lines. ${ }^{17}$

for a given quantile - that matter for optimal tax purposes.

${ }^{17}$ Theoretically speaking, the dominance tests carried out in Section 4 must be applied over ranges varying between 0 and some $z^{+}$. Statistically speaking, however, there is a general "information-less" problem in the tails of distributions that impedes such testing for values of $z$ close to 0 . Hence, statistically speaking, we must restrict the tests to a range that is lower-bounded somewhere above 0. See Davidson and Duclos (forthcoming) for a discussion of this. 


\subsection{Impact of efficiency-neutral tax reforms}

We now turn to the pro-poorness of revenue-neutral tax reforms. We first assume that the tax reforms are efficiency neutral, viz, that $\gamma=1$. Recall from page 17 that with $\gamma=1$ the tests for absolute and relative pro-poorness are equivalent.

\subsubsection{Efficiency-neutral reforms involving broad classes of goods}

Figure 3 presents the difference between the absolute pro-poor consumption dominance curves of Food and Transport, and this, for first and second orders of dominance. Except for rather low poverty lines, the lower bound of the confidence interval of this difference is always greater than zero, and hence a revenue-neutral tax reform that decreases food taxes and increases transportation taxes would be considered absolutely and relatively pro-poor for all $P \in \Pi^{1}(z)$ for a range of poverty lines extending to about 3 , and for all $P \in \Pi^{2}(z)$ for all poverty lines, except again for a bottom range of relatively small poverty lines. (As mentioned in footnote 17, little statistical information is usually available over intervals of rather low poverty lines, and it is therefore reasonable not to consider tests over such intervals.)

Figure 4 presents a similar difference, but this time between Food and Energy. For $s=1$, the lower bound of the confidence interval is greater than zero only up to about the official poverty line. Given this degree of statistical insignificance, it is therefore not immediate that one should consider as first-order pro-poor a revenue and efficiency neutral tax reform that decreases food taxation and increases energy taxation - or indeed the reverse. The concern is alleviated if we move to $s=2$ : the lower bound of the confidence interval is greater than zero after around $z=0.4$ and up to almost 3 .

Such tests of the effect of revenue and efficiency neutral tax reforms can be performed on every pair of goods. Table 2 summarizes the test results for the pairs of the three main goods. Here are some of the main findings.

- A tax reform that were to increase taxation on Transport and decrease taxation on Food would be absolutely and relatively first-order pro-poor over a wide range of poverty lines (0.145-3 for the estimates, $0.190-2.971$ for the statistically significant range). ${ }^{18}$

\footnotetext{
${ }^{18}$ Note that the poverty headcount at $z=0.145$ is around $0.3 \%$. Very little statistical information is thus available below that value, an indication of the information-less problem mentioned in footnote 17. It would also require a pro-poor judgement that would be almost strictly Rawlsian to reverse the pro-poor judgements implied by the tests over 0.145-3 and 0.190-2.971.
} 
- A tax reform that were to increase taxation on Transport and decrease taxation on Energy would also be absolutely and relatively first-order pro-poor over a wide range of poverty lines (0.137-3 for the estimates, $0.211-2.953$ for the statistically significant range).

- Applying statistical inference techniques can alter conclusions substantially. For instance, the estimates of Table 2 suggest that a tax reform that increases taxes on Energy and that decreases taxes on Food is pro-poor over a wide range of poverty lines ( 0.15 to 2.711$)$. This is considerably shortened $(0.206$ to 0.925 ) when one focusses on the range over which the ranking of the curves is statistically significant.

- If a reform is first-order pro-poor over a range of poverty lines that starts at 0 , then that range widens as we move to second-order pro-poorness see for instance the estimates shown in the first column, where the range of poverty lines over which a rise in Food taxes combined to a fall in Energy taxes is pro-poor increases from $0-0.15$ to $0-0.31$ as we move from first to second-order dominance.

- This last result, however, is true only when the ranking is valid for a firstorder range of poverty lines that right at 0 . Table 2 shows alternative instances of interesting relationships between the ranges over which firstorder and second-order dominance hold. For instance, an increase in Energy taxes and a fall in Food taxes (third column) is statistically first-order propoor over a range $0.206-0.925$ of poverty lines; that range becomes 0.383 2.753 for second-order dominance. Increasing the order of dominance thus reduces statistical significance over the lower values of poverty lines (the lower bound increases from 0.206 to 0.383 ), but it increases considerably (from 0.925 to 2.753 ) the upper bound of poverty lines over which the ranking of the curves is statistically significant.

\subsubsection{Efficiency-neutral reforms involving foodstuffs}

Let us now turn to the pro-poorness of revenue and efficiency neutral tax reforms involving solely food items. Figure 5 shows for instance the difference between the pro-poor consumption dominance curve of Cereals and that of Vegetables for first and second orders. The results are not statistically significant. Moreover, and as discussed above, when a reform is not statistically pro-poor within a range of poverty lines that starts at 0 , the statistically insignificant range 
can tend to widen as $s$ is increased. This can be seen in Figure 5 by noting that the area over which the confidence intervals overlap with the 0 line is pushed up and is wider with second-order than with first-order dominance.

The pro-poorness results involving the pairs of the three main food items are summarized in Table 3. They indicate that increasing Mexican taxes on Milk, meat and fish to decrease taxes on Cereals and/or on Vegetables would be pro-poor, both in terms of normative robustness and in terms of statistical significance, and this, whether we consider first or second-order dominance. The results of Table 3 also show that reforms involving any other combination of food items would not be so robustly pro-poor.

\subsection{Impact of efficiency non-neutral tax reforms}

We have assumed until now that tax reforms would be efficiency neutral and that $\gamma$ was unity. This assumes that the marginal deadweight loss of indirect taxation per dollar of tax raised is the same across all commodities. This is unlikely to hold since it implicitly assumes that compensated price elasticities are the same across all of the goods involved in the reform. Using (20), estimates of $\gamma$ can be obtained from elasticity estimates as

$$
\gamma_{i, j}=\frac{\left[1+\sum_{k=1}^{K} e_{k, i} \frac{t_{k}}{1+t_{i}}\right]}{\left[1+\sum_{k=1}^{K} e_{k, j} \frac{t_{k}}{1+t_{j}}\right]},
$$

where $e_{k, j}$ is the cross-price elasticity of a change in the price of good $j$ on the consumption of good $k$. Table 4 uses equation (27) and the cross-price elasticities across 9 major consumption categories provided in Regmi and Seale (2010) to estimate $\gamma_{i, j}$ for different $i, j$ pairs of goods. ${ }^{19}$ These estimates range from 0.83 and 1.2 .

To show the role of efficiency considerations in tax reforms, assume for simplicity and to start with that $\gamma=2$ - that is, that tax reforms are inefficient to the extent that each per capita dollar of tax raised on good $j$ to finance a tax decrease on good $i$ (see (21)) decreases per capita welfare by 1 (namely, by $\gamma-1$ ) dollar. Figure 6 shows the difference between the first-order absolute and relative propoor consumption dominance curves of Food and of Energy, when the dominance

\footnotetext{
${ }^{19}$ Regmi and Seale (2010) provide elasticity estimates for 114 countries using 1996 price data from the International Comparison Program.
} 
curve for Energy is weighted by $\gamma=2$. Setting $\gamma=2$ in that way implicitly supposes that the compensated price elasticity for Food is lower than that for Energy, and that the marginal deadweight loss from taxing Energy is thus greater than that from taxing Food.

Recall from Figure 4 that the difference between the first-order pro-poor consumption dominance curves of Food and of Energy was statistically positive only over a small range of poverty lines when $\gamma$ was set to 1 . With $\gamma=2$, Figure 6 shows that the difference in the absolute curves is now nowhere significantly positive. It is statistically significantly negative between around 0.7 and 2.2, which means that it would now be relatively pro-poor over that range of poverty lines to decrease Energy taxes and increase Food taxes.

The more inefficient it is to tax a good, the greater the tax rate that must be levied on that good to generate the tax revenues needed to decrease taxes on another, less price-elastic, good. If the more price-elastic good is not a luxury good, this makes the poor lose proportionately more from an inefficient tax reform than under an efficiency-neutral tax reform. This also makes increasing the price of the more price-elastic good less likely to be relatively pro-poor. Only when the price-elastic good is also a luxury good will an increase in its tax be conducive to greater relative pro-poorness. Since Energy is not a luxury good in Mexico, the greater the deadweight loss associated to taxing Energy, the more relatively propoor it will be to tax Food instead. This is true even though, as shown on Figure 1, Food may be less income elastic than Energy in Mexico.

Figure 6 also shows that the difference in the absolute consumption dominance curves is now everywhere positive, which also means that it is now absolutely propoor to tax Energy to finance a tax decrease on Food. The reverse also holds: it would be absolutely anti-poor to finance a tax decrease on Energy by raising taxes on Food. This is in sharp contrast to the above results for relative pro-poorness. If the more price-elastic good is a normal good, the absolute difference between the loss of the rich and that of the poor will be larger for $\gamma>1$ than for $\gamma=1$. Absolute pro-poorness of increasing taxes on the more price-elastic good is then also more likely to hold for $\gamma>1$.

A similar exercise is repeated in Figure 7, which shows the difference between the first-order relative and absolute pro-poor consumption dominance curve for Cereals and that for Vegetables. The curve for Vegetables (presumably the more price-elastic good) is being weighted by $\gamma=2$. This can be compared to Figure 5 in which $\gamma=1$. With $\gamma=2$, it now possible to declare that a revenue-neutral reform that increases taxes on Cereals and decreases them on Vegetables is firstorder relatively pro-poor. The reasoning is the same as before: Vegetables are not 
a luxury good, and it is thus better not to raise taxes on that price-elastic good. But a revenue-neutral reform that decreases taxes on Cereals and increases them on Vegetables would be first-order absolutely pro-poor over a wide range of poverty lines, again because, for $\gamma>1$, that would maximize the distance between the absolute loss of the rich and that of the poor.

\subsection{Trading off efficiency and distribution}

The trade-off between efficiency (which is related to price elasticities) and the shape of the $C D$ curves (which is related to income elasticities) can be usefully exemplified by the following ratio $\delta_{i, j}^{\eta: s}(z)$ of $C D$ curves:

$$
\delta_{i, j}^{\eta: s}(z)=\frac{C D_{i}^{\eta: s}(z)}{C D_{j}^{\eta: s}(z)} .
$$

Using (21) and supposing that $C D_{j}^{\eta: s}(z)>0$, we then find that a revenue-neutral tax reform that reduces taxation on good $i$ and increases taxation on good $j$ is $\eta$-pro-poor $(\eta \in\{A, R\})$ if and only if

$$
\delta_{i, j}^{\eta: s}(z) \geq \gamma_{i, j} \forall z \in\left[0, z^{+}\right],
$$

where $\gamma_{i, j}$ is the efficiency cost of taxing good $j$ relative to good $i$. If $C D_{j}^{\eta: s}(z)<$ 0 , then the condition is rather that

$$
\delta_{i, j}^{\eta: s}(z) \leq \gamma_{i, j} \forall z \in\left[0, z^{+}\right] .
$$

When $C D_{j}^{\eta: s}(z)>0$, condition (29) shows that we can interpret $\delta_{i, j}^{\eta: s}(z)$ as those critical efficiency ratios that must not be exceeded by $\gamma_{i, j}$ for a tax reform that reduces taxation on good $i$ (and increases taxation on good $j$ ) to be declared pro-poor. A reverse use of $\delta_{i, j}^{\eta: s}(z)$ can also be made: we can interpret $\delta_{i, j}^{\eta: s}(z)$ as the critical efficiency ratios that must be surpassed by $\gamma_{i, j}$ for a tax reform that reduces taxation on good $j$ (and increases taxation on good $i$ ) to be declared propoor. When $C D_{j}^{\eta: s}(z)<0$, condition (30) shows that we can interpret $\delta_{i, j}^{\eta: s}(z)$ as critical efficiency ratios that must be exceeded by $\gamma_{i, j}$ for a tax reform that reduces taxation on good $i$ (and increases taxation on good $j$ ) to be declared pro-poor.

Figure 8 shows the $\delta^{\eta: s}(z)$ curves for a reform involving Food and Energy. Let us set an upper bound $z^{+}=2$ to the range of poverty lines. Consider first the absolute pro-poorness of a revenue-neutral reform that decreases taxation on Food and increases taxation on Energy. Since $C D_{\text {Energy }}^{A: s}(z)<0$ (see Figure 2), 
for such a reform to be absolutely pro-poor according to Figure 8, the efficiency $\operatorname{cost} \gamma_{i, j}$ of taxing energy relative to food must be larger than 1.7. This statistic is given by the maximal height of the upper bound of the confidence intervals shown in Figure 8. At that maximal height, $\gamma_{i, j}$ is indeed statistically greater than $\delta_{i, j}^{\eta: s}(z)$, and condition (30) is therefore statistically verified. With $\gamma_{i, j}$ larger than 1.7 , the absolute fall in average real income will always be larger than the fall in the poor's real income, no matter what value of $z$ below 2 is selected. This is because a $\gamma_{i, j}$ larger than 1.7 will always involve a sufficiently large increase in the tax on Energy to compensate for the effect of the fall in Food taxation.

Consider then a revenue-neutral reform that increases taxation on food and decreases taxation on energy, for the same upper bound of $z^{+}=2$. For such a reform to be absolutely pro-poor according to Figure 8, the efficiency cost $\gamma_{i, j}$ of taxing energy relative to food must be lower than 0.79 . This statistic is now given by the minimal height of the lower bound of the confidence intervals, for reasons that are the reverse of those just mentioned.

A similar exercise can be carried out for relative pro-poorness, but with quite different results. Since we now have that $C D_{\text {Energy }}^{R: s}(z)>0$ (see Figure 1), the condition to check is (29). A revenue-neutral reform that decreases taxation on Food and increases taxation on Energy will be relatively pro-poor according to Figure 8 if the efficiency cost $\gamma_{i, j}$ of taxing energy relative to food is lower than around 0.5. Conversely, a revenue-neutral reform that increases taxation on Food and decreases taxation on Energy will be relatively pro-poor if the efficiency cost $\gamma_{i, j}$ of taxing energy relative to food is greater than 4.5. When $0.5 \leq \gamma_{i, j} \leq 4.5$, the effect on relative pro-poorness of a tax reform involving Food and Energy is either statistically insignificant or normatively sensitive to the choice of indices and poverty lines between 0 and 2 .

\section{Conclusion}

This paper develops a methodology for checking wether indirect tax reforms can be considered to be pro-poor or not. The methodology extends previous stochastic dominance techniques and enables one to characterize tax reforms on the basis of wide spectra of possible views of "pro-poorness". This is done for both absolute and relative pro-poorness, for ranges of possible poverty lines, and for different degrees of distributional sensitivity to the differentiated impact of tax reforms across pre-reform values of welfare. The paper's framework allows for absolute pro-poorness to differ from the usual objectives of absolute poverty 
reduction. Statistical inference techniques are also provided to make these tools empirically applicable. Unlike previous papers, the statistical methods developed in this paper take into account the joint distribution of total and specific commodity consumption levels since they address the pro-poor impacts of price changes. The current paper also provides measurement and statistical methods that help deal with the trade-off between efficiency and distribution.

The methodology is applied to the pro-poorness of possible reforms of Mexico's indirect tax system, both across broad classes of goods and across foodstuffs. This leads to the characterizations of a number of possible pro-poor indirect tax reforms. The results also show that whether indirect tax reforms can be deemed to be pro-poor can depend to an important extent on the type of distributional and/or pro-poor views that are applied to the analysis, and that it is therefore important to make such views clear when making policy recommendations for pro-poor tax reforms. The results further indicate that whether indirect tax reforms are propoor depends 1) on whether government revenue neutrality is maintained, and 2) on the size of the deadweight gains/losses incurred in the trade-off between balancing efficiency and redistribution.

For instance, we find that, regardless of the good, tax reductions are never absolutely pro-poor in Mexico if the change in average wellbeing is used as an absolute norm; this is because none of the goods is an inferior good in the data. However, tax reductions on goods such as food and energy are relatively pro-poor. Furthermore, a revenue-neutral and efficiency-neutral tax reform that decreases food taxes and increases transportation taxes is both absolutely and relatively propoor. The pro-poorness of an efficiency-non-neutral tax reform involving food and energy depends, however, significantly on the relative efficiency cost of taxing the two goods.

\section{Appendix}

\subsection{Proof of Theorem 1}

Let

$$
P^{R}(z)=\int_{-\infty}^{\infty} p\left(\frac{y}{1+g}, z\right) d F(y)
$$

and

$$
P^{A}(z)=\int_{-\infty}^{\infty} p(y-a, z) d F(y)
$$


Using (5), (11), (12), (13) and (14), we obtain for $\eta=R, A$ :

$$
\left.\frac{\partial P^{\eta}(z)}{\partial t_{i}}\right|_{g, a=0}=-X_{i}(q) \int_{-\infty}^{\infty} p^{(1)}(y, z) C D_{i}^{\eta: 1}(y) d y .
$$

The sufficiency condition for $s=1$ is proved from (33) by noting that $p^{(1)}(y, z)$ is negative. We then need to integrate by parts $\int_{-\infty}^{\infty} p^{(1)}(y, z) C D_{i}^{\eta: 1}(y) d y$ :

$$
\begin{aligned}
\int_{-\infty}^{\infty} p^{(1)}(y, z) C D_{i}^{\eta: 1}(y) d y= & \left.p^{(1)}(y, z) C D_{i}^{\eta: 2}(y)\right|_{-\infty} ^{\infty} \\
& -\int_{-\infty}^{\infty} p^{(2)}(y, z) C D_{i}^{\eta: 2}(y) d y
\end{aligned}
$$

We know that $C D_{i}^{\eta: 2}(0)=0$ and that $p^{1}(\infty, z)=0$. The first term on the r.h.s. of the above is thus nil. Consequently, equation (34) may be rewritten as

$$
\int_{-\infty}^{\infty} p^{(1)}(y, z) C D_{i}^{\eta: 1}(y) d y=-\int_{-\infty}^{\infty} p^{(2)}(y, z) C D_{i}^{\eta: 2}(y) d y
$$

Now, assume that we have:

$$
\int_{-\infty}^{\infty} p^{(1)}(y, z) C D_{i}^{\eta: 1}(y) d y=(-1)^{s-2} \int_{-\infty}^{\infty} p^{(s-1)}(y, z) C D_{i}^{\eta: s-1}(y) d y .
$$

Integrating by parts equation (36), we get

$$
\begin{aligned}
\int_{-\infty}^{\infty} p^{(1)}(y, z) C D_{i}^{\eta: 1}(y) d y= & \left.(-1)^{s-2} p^{(s-1)}(y, z) C D_{i}^{\eta: s-1}(y)\right|_{-\infty} ^{\infty} \\
& -(-1)^{s-2} \int_{-\infty}^{\infty} p^{(s)}(y, z) C D_{i}^{\eta: s}(y) d y
\end{aligned}
$$

$C D_{i}^{\eta: s}(0)=0$ and $p^{(s-1)}(\infty, z)=0$ is implied by the definition of $\infty$ and by (2). We can rewrite (37) as

$$
\int_{-\infty}^{\infty} p^{(1)}(y, z) C D_{i}^{\eta: 1}(y) d y=(-1)^{s-1} \int_{-\infty}^{\infty} p^{(s)}(y, z) C D_{i}^{\eta: s}(y) d y .
$$

Equation (35) obeys the relation depicted in (36). We have shown that if (36) is true then equation (38) is also true. This implies that equation (38) is true for 
$\eta=R, A$ and for all integer $s \in\{2,3, \ldots, s-1\}$. From equation (33) and (38), we get

$$
\left.\frac{\partial P^{\eta}(z)}{\partial t_{i}}\right|_{g, a=0}=(-1)^{s} X_{i}(q) \int_{-\infty}^{\infty} p^{(s)}(y, z) C D_{i}^{\eta: s}(y) d y .
$$

This last equation together with equation (2) proves the sufficiency of the condition.

In order to establish necessity, consider the set of functions $p(y, z)$ for which the $(s-1)$ th derivative (with $p^{(0)}(y, z)=p(y, z)$ ) is of the following form

$$
p^{(s-1)}(y, z)=\left\{\begin{array}{cc}
(-1)^{s-1} \epsilon & y \leq \bar{y} \\
(-1)^{s-1}(\bar{y}+\epsilon-y) & \bar{y}<y \leq \bar{y}+\epsilon \\
0 & y>\bar{y}+\epsilon .
\end{array}\right.
$$

Poverty indices whose function $p(y, z)$ has the particular above form for $p^{(s-1)}(y, z)$ belong to $\Pi^{s}$. This yields:

$$
p^{(s)}(y, z)=\left\{\begin{array}{cc}
0 & y<\bar{y} \\
(-1)^{s} & \bar{y}<y<\bar{y}+\epsilon \\
0 & \bar{y}>\bar{y}+\epsilon .
\end{array}\right.
$$

Imagine now that $C D_{i}^{\eta: s}(y)<0$ on an interval $[\bar{y}, \bar{y}+\epsilon]$ for $\bar{y}<z^{+}$and for $\epsilon$ that can be arbitrarily close to 0 . For $p(y, z)$ defined as in (40), expression (39) is then positive and the marginal tax reform induces a marginal increase of poverty. Hence, it cannot be that $C D_{i}^{\eta: s}(y)<0$ for $y \in[\bar{y}, \bar{y}+\epsilon]$ when $\bar{y}<z^{+}$. This proves the necessity of the condition.

\subsection{Proof of Theorem 3}

$\widehat{C D}^{s}\left(x_{k} ; z\right)$ is a consistent estimator of $C D^{s}\left(x_{k} ; z\right)$ by the existence of the first population moment of $x_{k}(y)(z-y)_{+}^{s-2}$ and the law of large numbers. $\widehat{C D}^{s}\left(x_{k} ; z\right)$ is $N^{0.5}$ consistent and asymptotically normal by the existence of the second population moment and the central limit theorem, with asymptotic variance given by (24) by simple calculation. 


\subsection{Proof of Theorem 4}

Note first that $E\left[\widehat{C D}^{1}\left(x_{k} ; z\right)\right]=\int \kappa_{h}(z-y) x_{k}(y) f(y) d y$. Denoting $t=$ $h^{-1}(z-y)$ and expanding around $t_{0}=0$, for small $h$ this is approximately equal to

$$
\begin{aligned}
& E\left[\widehat{C D}^{1}\left(x_{k} ; z\right)\right] \\
\simeq & \int \kappa(t)\left[C D^{1}\left(x_{k} ; z\right)-t h C D^{1 \prime}\left(x_{k} ; z\right)(z)+0.5 t^{2} h^{2} \widehat{C D}^{1 \prime \prime}\left(x_{k} ; z\right)(z)\right] d t \\
= & +0.5 h^{2} \widehat{C D}^{1 \prime \prime}\left(x_{k} ; z\right)(z) c_{\kappa}
\end{aligned}
$$

since $\int \kappa(u) d u=1, \int u \kappa(u) d u=0$, and $\int u^{2} \kappa(u) d u=c_{\kappa}$. Hence, the bias $E\left[\widehat{C D}^{1}\left(x_{k} ; z\right)\right]-C D^{1}\left(x_{k} ; z\right)$ is given by $0.5 h^{2} \widehat{C D}^{1 \prime}\left(x_{k} ; z\right) c_{\kappa}$.

By (25), note that $\widehat{C D}^{1}\left(x_{k} ; z\right)$ is a sum of iid variables to which we may apply the central limit theorem and show asymptotic normality. We also have that

$$
\begin{aligned}
& N \operatorname{var}\left(\widehat{C D}^{1}\left(x_{k} ; z\right)\right) \\
= & \operatorname{var}\left(\kappa_{h}(z-y) x_{k}(y)\right)=E\left[\kappa_{h}(z-y)^{2}\left(x_{k}(y)\right)^{2}\right]-E\left[\widehat{C D}^{1}\left(x_{k} ; z\right)\right]^{2} \\
= & \int_{y} \kappa_{h}(z-y)^{2}\left(x_{k}(y)\right)^{2} d F(y)-E\left[\widehat{C D}^{1}\left(x_{k} ; z\right)\right]^{2} \\
= & \int_{u} h^{-2} \kappa(u)^{2}\left(x_{k}(z-u h)\right)^{2} d F(z-u h)-E\left[\widehat{C D}^{1}\left(x_{k} ; z\right)\right]^{2}
\end{aligned}
$$

where the last expression is obtained by substituting $u$ for $h^{-1}(z-y)$. For small $h,(44)$ is approximately equal to

$$
\begin{aligned}
& N \operatorname{var}\left(\widehat{C D}^{1}\left(x_{k} ; z\right)\right) \\
\cong & \int_{u} h^{-1} \kappa(u)^{2}\left(x_{k}(z)\right)^{2} f(z) d u-E\left[\widehat{C D}^{1}\left(x_{k} ; z\right)\right]^{2} \\
= & h^{-1} f(z)\left(x_{k}(z)\right)^{2} \int_{u} \kappa(u)^{2} d u-E\left[\widehat{C D}^{1}\left(x_{k} ; z\right)\right]^{2} \\
\cong & h^{-1} f(z)\left(x_{k}(z)\right)^{2} \int_{u} \kappa(u)^{2} d u \\
= & h^{-1} f(z) c_{k}(z) \int \kappa(u)^{2} d u .
\end{aligned}
$$


Hence,

$$
\begin{aligned}
& \lim _{N \rightarrow \infty} \operatorname{Nhvar}\left(\widehat{C D}^{1}\left(x_{k} ; z\right)-C D^{1}\left(x_{k} ; z\right)-h^{2} B_{k}\right) \\
= & f(z) c_{k}(z) \int \kappa(u)^{2} d u=V_{k}(z),
\end{aligned}
$$

which concludes the proof.

\section{References}

Ahmad, E. AND N. STERn (1984): "The Theory of Reform and Indian Indirect Taxes," Journal of Public Economics, 25, 259-98.

AraAr, A., J.-Y. Duclos, M. Audet, AND P. MAKdissi (2007): "Has Mexican growth been pro-poor?" Tech. rep., Université Laval.

(2009): "Testing for pro-poorness of growth, with an application to Mexico," Review of Income and Wealth, 55, 853-881.

Audet, M., P. Makdissi, A. AraAr, And J.-Y. Duclos (2007): "Propoor food taxation and subsidy reforms in Mexico," in Social Perspectives, Proceedings of the Eight Symposium on "Capital Humano, Crecimiento, Pobreza: Problemática Mexicana”, Monterrey, Mexico, October 12 and 13, 2006, vol. 9, 49-64.

Bennett, S. AND L. Gilson (2001): "Health financing: designing and implementing pro-poor policies," Tech. rep., DFID, http://www.dfidhealthrc.org/publications/health_ sector_financing/Health_financing_pro-poor.pdf.

Bourguignon, F. (2003): "The Poverty-Growth-Inequality Triangle," in Conference on Poverty, Inequality and Growth, Paris: Agence française de développement.

Bruno, M., M. Ravallion, And L. SQuire (1998): "Equity and Growth in Developing Countries: Old and New Perspectives on the Policy Issues," in Income Distribution and High-Quality Growth, ed. by V. Tanzi and K. C. (eds.), Cambridge: MIT Press.

Chakravarty, S. (1983): "Ethically Flexible Measures of Poverty," Canadian Journal of Economics, XVI, 74-85. 
Clark, S., R. Hemming, And D. Ulph (1981): "On Indices for the Measurement of Poverty," The Economic Journal, 91, 515-526.

DAVIDSON, R. AND J.-Y. DUClos (forthcoming): “Testing for Restricted Stochastic Dominance," Econometric Reviews.

Dollar, D. AND A. KRAAY (2002): "Growth Is Good for the Poor," Journal of Economic Growth, 7, 195-225.

DonAlDSON, D. (1992): "On the Aggregation of Money Measures of WellBeing in Applied Welfare Economics," Journal of Agricultural and Resource Economics, 17, 88-102.

Duclos, J.-Y. (2009): "What is "Pro-Poor"?" Social Choice and Welfare, $32,37-58$.

Duclos, J.-Y. And A. AraAR (2006): Poverty and Equity: Measurement, Policy, and Estimation with DAD, Berlin and Ottawa: Springer and IDRC.

Duclos, J.-Y. AND P. MAKDISSI (2004): "Restricted and Unrestricted Dominance for Welfare, Inequality, and Poverty Orderings," Journal of Public Economic Theory, 6, 145-164.

Duclos, J.-Y., P. MAKdissi, AND Q. Wodon (2008): "SociallyImproving Tax Reforms," International Economic Review, 49, 15071539.

EAstwood, R. And M. Lipton (2001): "Pro-poor Growth and ProGrowth Poverty Reduction: What do they Mean? What does the Evidence Mean? What can Policymakers do?" Asian Development Review, $19,1-37$.

EsSAMA-NsSAH, B. (2005): "A unified framework for pro-poor growth analysis," Economics Letters, 89, 216-221.

Fishburn, P. AND R. Willig (1984): “Transfer Principles in Income Redistribution," Journal of Public Economics, 25, 323-328.

Foster, J., J. Greer, AND E. Thorbecke (1984): "A Class of Decomposable Poverty Measures," Econometrica, 52, 761-776.

HÄrdle, W. (1990): Applied Nonparametric Regression, vol. XV, Cambridge, cambridge university press ed. 
KaKWAni, N., S. KhandKer, And H. Son (2003): "Poverty Equivalent Growth Rate: With Applications to Korea and Thailand," Tech. rep., Economic Commission for Africa.

Kakwani, N. And E. Pernia (2000): "What is Pro Poor Growth?" Asian Development Review, 18, 1-16.

KaKWANI, N. AND H. H. Son (2008): "Poverty Equivalent Growth Rate," Review of Income and Wealth, 54, 643-655.

KING, M. (1983): "Welfare Analysis of Tax Reforms Using Household Data," Journal of Public Economics, 21, 183-214.

KLASEN, S. (2004): "In Search of the Holy Grail: How to Achieve Pro-Poor Growth?" in Toward Pro Poor Policies-Aid, Institutions, and Globalization, ed. by B. Tungodden, N. Stern, and I. Kolstad, New York: Oxford University Press, 63-94.

(2008): "Economic Growth and Poverty Reduction: Measurement Issues using Income and Non-Income Indicators," World Development, $36,420-445$.

Kolm, S.-C. (1976): "Unequal Inequalities, I," Journal of Economic Theory, $12,416-42$.

Liberati, P. (2003): "Poverty Reducing Reforms and Subgroups Consumption Dominance Curves," Review of Income and Wealth, 49, 589601.

MAKDissi, P. AND Q. Wodon (2002): "Consumption Dominance Curves: Testing for the Impact of Indirect Tax Reforms on Poverty," Economics Letters, 75, 227-35.

MAYSHAR, J. AND S. YITZHAKI (1996): "Dalton-Improving Tax Reform: When Households Differ in Ability and Needs," Journal of Public Economics, 62, 399-412.

MCCulloch, N. AND B. BAulCH (1999): "Tracking pro-poor growth," Tech. Rep. ID21 insights \#31, Sussex, Institute of Development Studies.

NAVAJAS, F. AND A. PORTO (1994): "Budget shares, distributional characteristics and the direction of tax reform," Economics Letters, 45, 475 479 .

Pen, J. (1971): Income Distribution: facts, theories, policies, New York: Preaeger. 
RAO, R. (1973): Linear Statistical Inference and Its Applications, New York: John Wiley and Sons Inc.

RAVALLION, M. (2001): "Growth, Inequality and Poverty: Looking Beyond Averages," World Development, 29, 1803-15.

Ravallion, M. And S. Chen (2003): "Measuring Pro-poor Growth," Economics Letters, 78, 93-99.

Ravallion, M. And G. DatT (2002): "Why Has Economic Growth Been More Pro-poor in Some States of India Than Others?" Journal of Development Economics, 68, 381-400.

Regmi, A. And J. L. J. Seale (2010): "Cross-Price Elasticities of Demand Across 114 Countries," Technical Bulletin 59870, United States Department of Agriculture, Economic Research Service.

SANTORO, A. (2007): "Marginal commodity tax reforms: a survey," Journal of Economic Surveys, 21, 827-848.

Son, H. (2004): “A note on pro-poor growth,” Economics Letters, 82, 307314.

UNDP (2009): "IPC-IG Collection of One-Pagers," Tech. rep., International Policy Centre for Inclusive Growth, Brazilia, Brazil.

United Nations (2000): A Better World for All, New York.

Watts, H. W. (1968): “An Economic Definition of Poverty," in Understanding Poverty, ed. by D. Moynihan, New York: Basic Books.

Wildasin, D. (1984): "On Public Good Provision With Distortionary Taxation," Economic Inquiry, 22, 227-243.

WORLD BANK (2002): “Globalization, Growth, and Poverty,” World Bank Policy Research Report.

(2004): "Poverty in Mexico: An Assessment of Trends, Conditions, and Government Strategy," Tech. Rep. 28612-ME, Washington D.C.

YitzhaKi, S. AND J. SLemrod (1991): "Welfare Dominance: An Application to Commodity Taxation," American Economic Review, LXXXI, 480-96.

YITZHAKI, S. AND W. THIRSK (1990): "Welfare Dominance and the Design of Excise Taxation in the Cote D'Ivoire," Journal of Development Economics, 33, 1-18. 
Table 1: Shares (by population quintiles) of total expenditures on different goods and services

\begin{tabular}{l|r|r|r|r|r}
\hline \hline & \multicolumn{5}{|c}{ Expenditure shares in \% } \\
\hline Quintile & Poorest & 2 & 3 & 4 & Richest \\
\hline Goods and services & & & & & \\
Food & 42.99 & 28.88 & 22.61 & 17.20 & 8.04 \\
Energy & 6.13 & 5.09 & 4.45 & 3.87 & 2.64 \\
Transport & 11.74 & 11.90 & 12.09 & 13.32 & 12.42 \\
Other goods & 39.14 & 54.13 & 60.85 & 65.61 & 76.9 \\
\hline Shares offood expenditures & & & & & \\
Cereals & 25.88 & 23.91 & 21.20 & 18.95 & 15.90 \\
Milk, meat and fish & 28.66 & 37.92 & 41.90 & 45.61 & 46.44 \\
Vegetables & 19.30 & 18.30 & 17.63 & 17.86 & 17.66 \\
Other food items & 26.16 & 19.87 & 19.27 & 17.58 & 20.00 \\
\hline
\end{tabular}

Table 2: Intervals of poverty lines over which a revenue and efficiency neutral tax reform that decreases taxes on row goods and that increases taxes on column goods can be considered pro-poor (absolutely and relatively speaking)

\begin{tabular}{|l|c|c|c|}
\hline & \multicolumn{3}{|c|}{ First-order dominance } \\
\hline Goods & Food & Transport & Energy \\
\hline Transport & - & $0.145-3.000+$ & $0.150-2.711$ \\
& - & $(0.190-2.971)$ & $(0.206-0.925)$ \\
Energy & $0.000-0.145$ & - & $0.000-0.137$ \\
& & - & - \\
\hline \hline \multirow{2}{*}{ Goods } & $0.000-0.150$ & $0.137-3.000+$ & - \\
\hline Food & \multicolumn{3}{|c|}{ Second-order dominance } \\
& - & $0.279-3.000+$ & $0.310-3.000+$ \\
Transport & - & $(0.375-3.000+)$ & $(0.383-2.753)$ \\
& $0.000-0.279$ & - & $0.000-0.269$ \\
Energy & - & - & - \\
& $0.000-0.310$ & $0.269-3.000+$ & - \\
\hline
\end{tabular}

Note: The intervals that appear on the first line of each cell are estimates. The intervals over which the results are statistically significant at a 95\% level are shown within parentheses on the second line of each cell. 
Table 3: Intervals of poverty lines over which a revenue and efficiency neutral tax reform that decreases taxes on row goods and that increases taxes on column goods can be considered pro-poor

\begin{tabular}{|l|c|c|c|}
\hline & \multicolumn{3}{|c|}{ First-order dominance $(s=1)$} \\
\hline Goods & Cereals & Milk, Meat and Fish & Vegetables \\
\hline Cereals & - & $0.000-2.231$ & $0.000-0.171$ \\
Milk, Meat and Fish & - & $(0.010-2.159)$ & $(0.000-0.107)$ \\
& $-231-3.000+$ & - & $0.010-0.012$ \\
Vegetables & $(2.294-3.000+)$ & - & - \\
& $0.171-0.588$ & $0.012-2.421$ & - \\
\hline & $(0.271-0.458)$ & $(0.044-2.040)$ & - \\
\hline Goods & \multicolumn{2}{|c|}{ Second-order dominance $(s=2)$} \\
\hline Cereals & Cereals & Milk, Meat and Fish & Vegetables \\
& - & $0.000-3.000+$ & $0.000-0.328$ \\
Milk, Meat and Fish & - & $(0.219-3.000+)$ & - \\
Vegetables & - & - & $0.067-0.112$ \\
& $0.328-0.701$ & $0.067-3.000+$ & - \\
\hline
\end{tabular}

Note: The intervals that appear on the first line of each cell are estimates. The intervals over which the results are statistically significant at a $95 \%$ level are shown within parentheses on the second line of each cell. 
Table 4: Estimates of the efficiency costs of tax reforms using estimated price elasticities

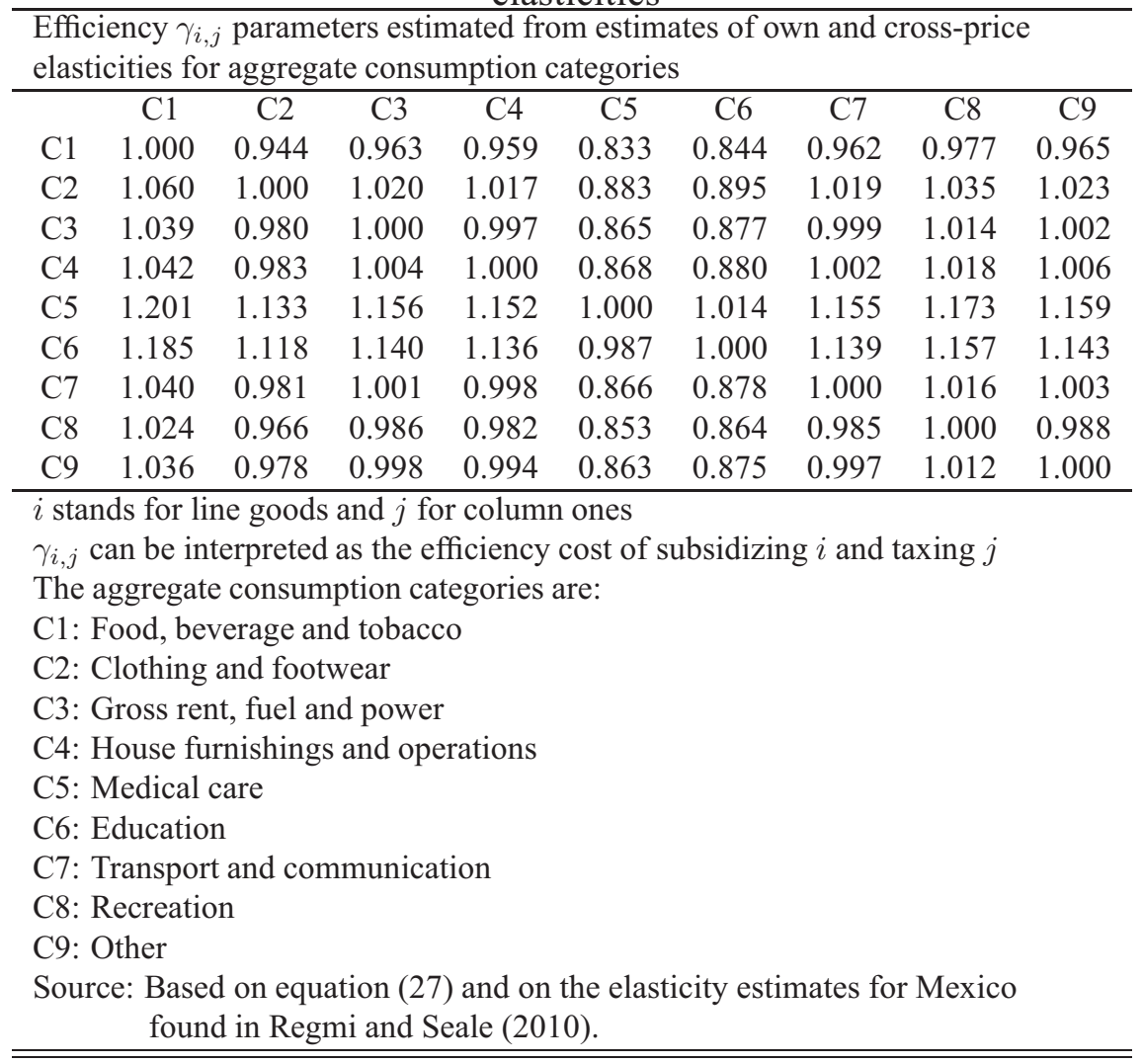


Figure 1: $90 \%$ two-sided confidence intervals around relative pro-poor consumption dominance curves, $C D^{R: s}(z)$

First-order dominance $(s=1)$

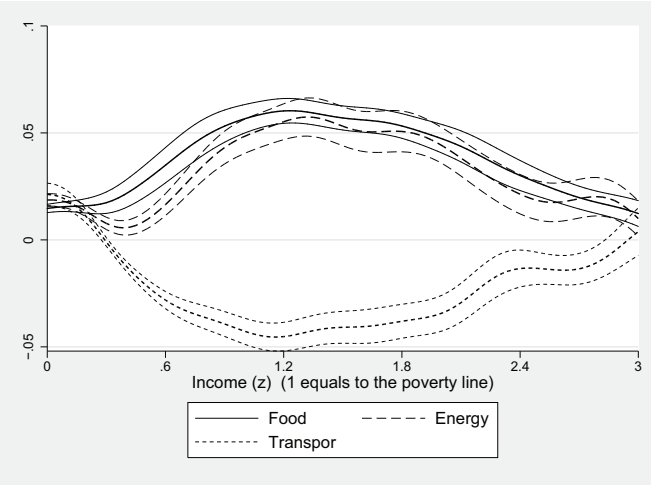

Second-order dominance $(s=2)$

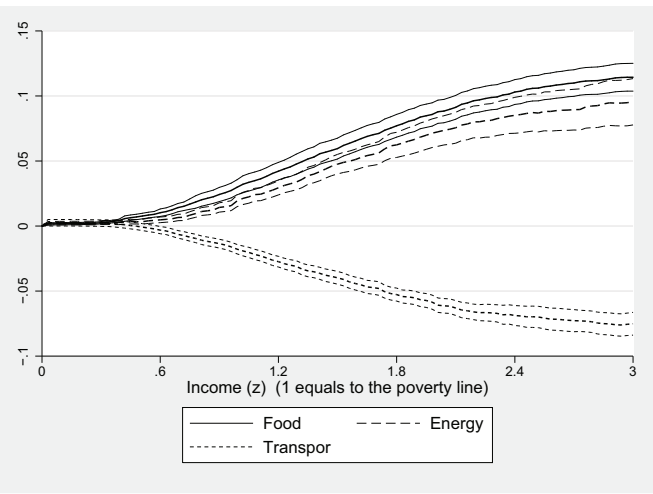

Figure 2: $90 \%$ two-sided confidence intervals around absolute pro-poor consumption dominance curves, $C D^{A: s}(z)$

First-order dominance $(s=1)$

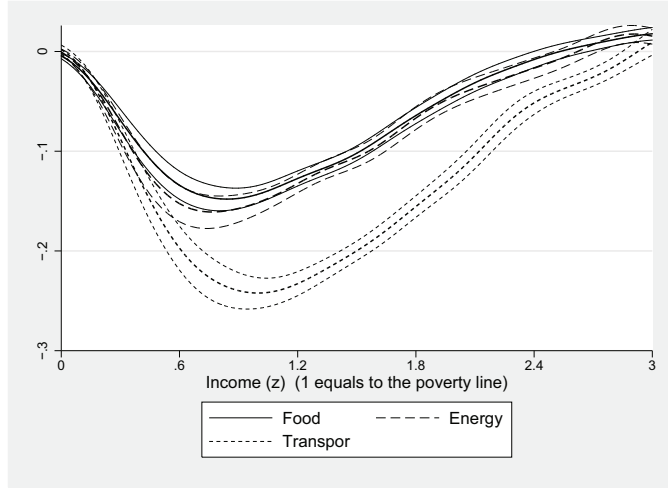

Second-order dominance $(s=2)$

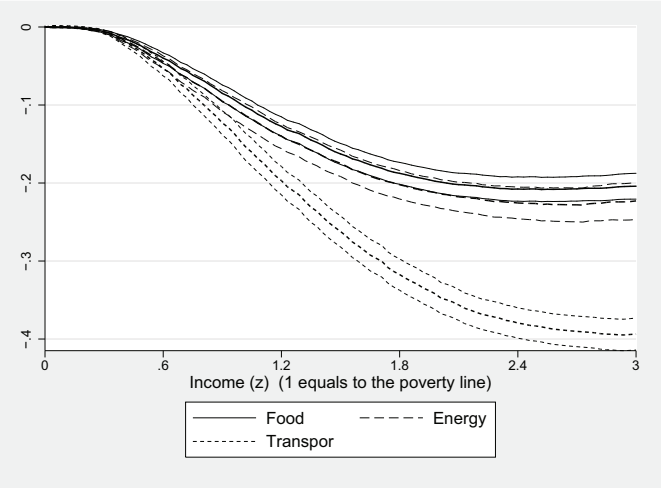


Figure 3: Difference between absolute pro-poor consumption dominance curves

$C D_{\text {Food }}^{A: s=1}(z)-C D_{\text {Transport }}^{A: s=1}(z)$

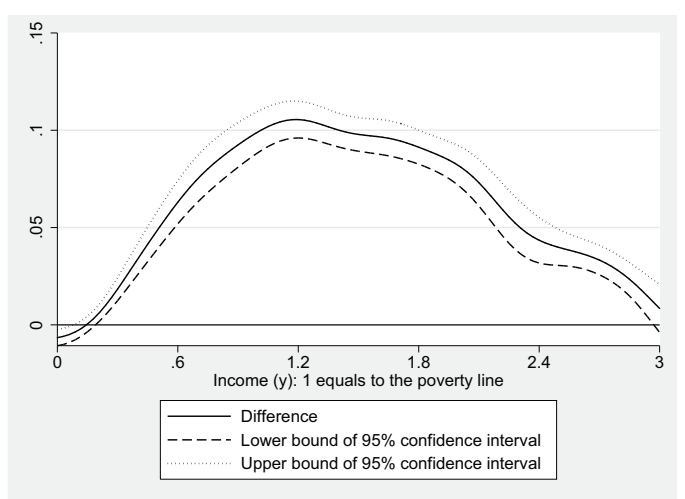

$C D_{\text {Food }}^{A: s=2}(z)-C D_{\text {Transport }}^{A: s=2}(z)$

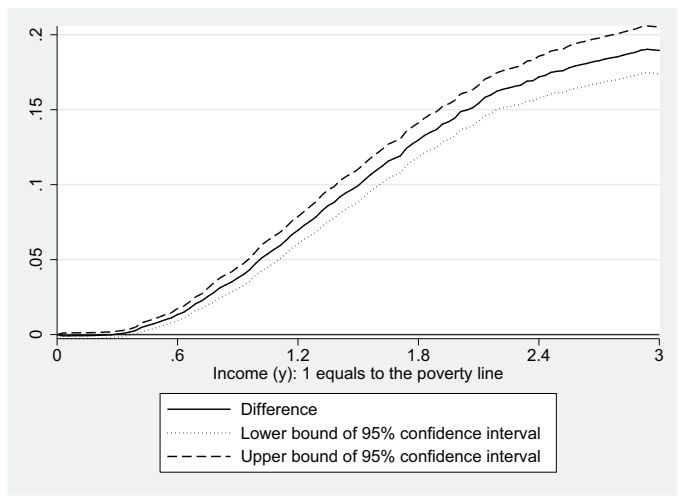

Figure 4: Difference between absolute pro-poor consumption dominance curves

$$
C D_{\text {Food }}^{A: s=1}(z)-C D_{\text {Energy }}^{A: s=1}(z)
$$

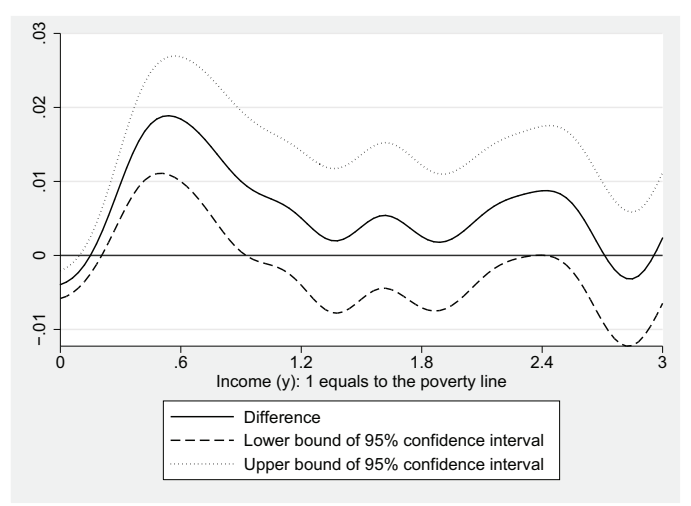

$$
C D_{\text {Food }}^{A: s=2}(z)-C D_{\text {Energy }}^{A: s=2}(z)
$$

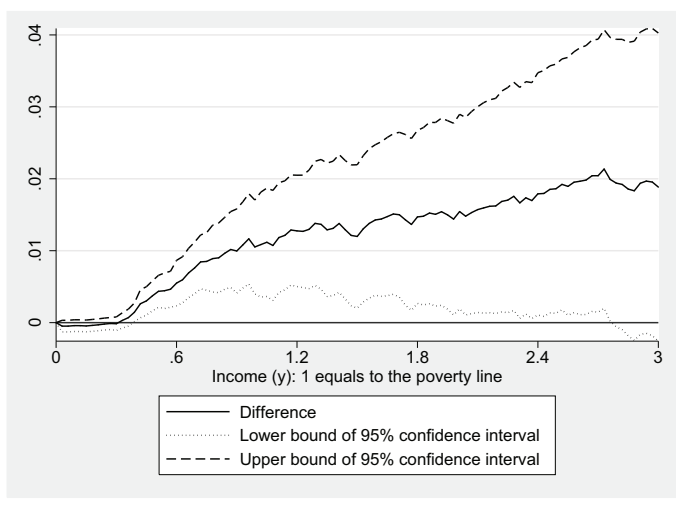


Figure 5: Difference between pro-poor consumption dominance curves $C D_{\text {Cereals }}^{A: s=1}(z)-C D_{V \text { egetables }}^{A: s=1}(z)$ $C D_{\text {Cereals }}^{A: s=2}(z)-C D_{V \text { egetables }}^{A: s=2}(z)$
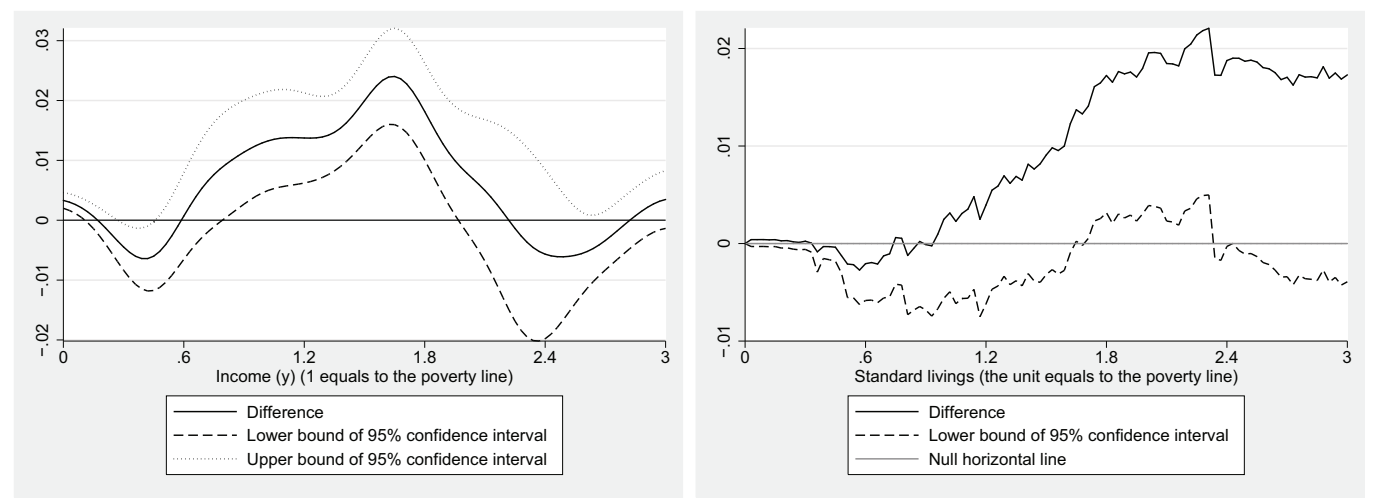

Figure 6: Difference between pro-poor consumption dominance curves, assuming that the deadweight loss from taxing Energy is twice as large as that from taxing Food

Relative pro-poorness

$C D_{\text {Food }}^{R: s=1}(z)-2 C D_{\text {Energy }}^{R: s=1}(z)$

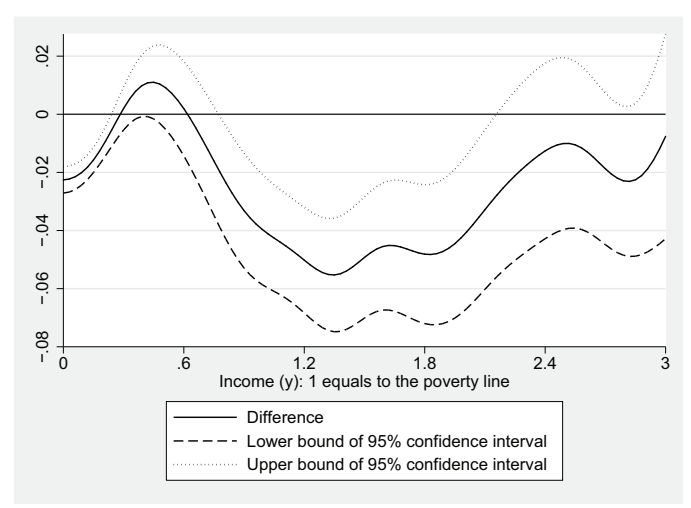

Absolute pro-poorness $C D_{\text {Food }}^{A: s=1}(z)-2 C D_{\text {Energy }}^{A: s=1}(z)$

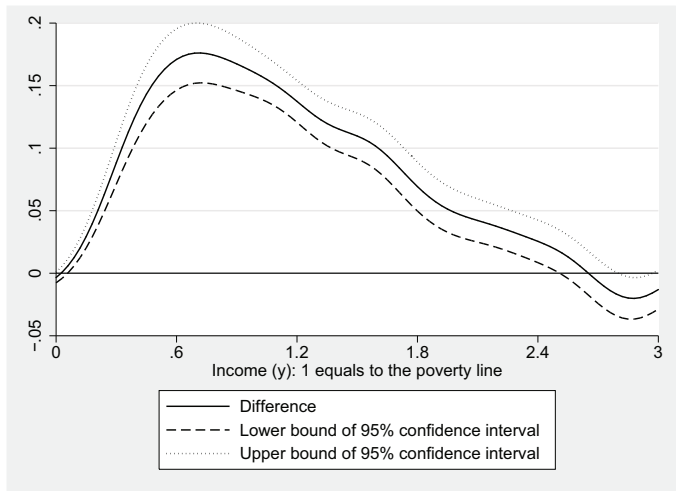


Figure 7: Difference between pro-poor consumption dominance curves, assuming that the deadweight loss from taxing Vegetables is twice as large as that from taxing Cereals

$C D_{\text {Cereals }}^{R: s=1}(z)-2 C D_{\text {Vegetables }}^{R: s=1}(z)$

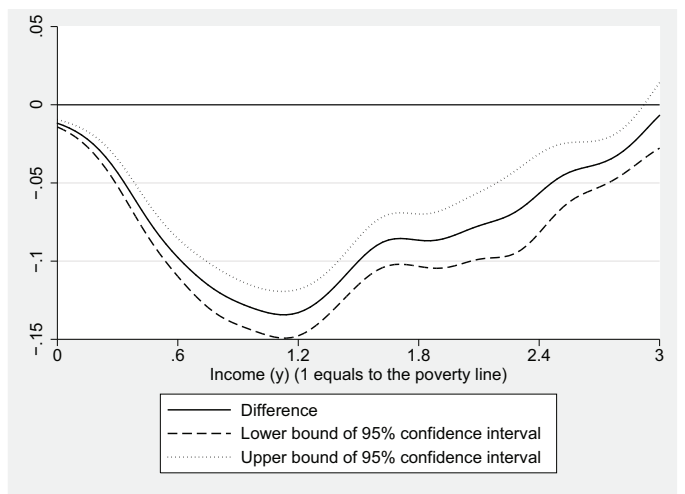

$C D_{\text {Cereals }}^{A: s=1}(z)-2 C D_{\text {Vegetables }}^{A: s=1}(z)$

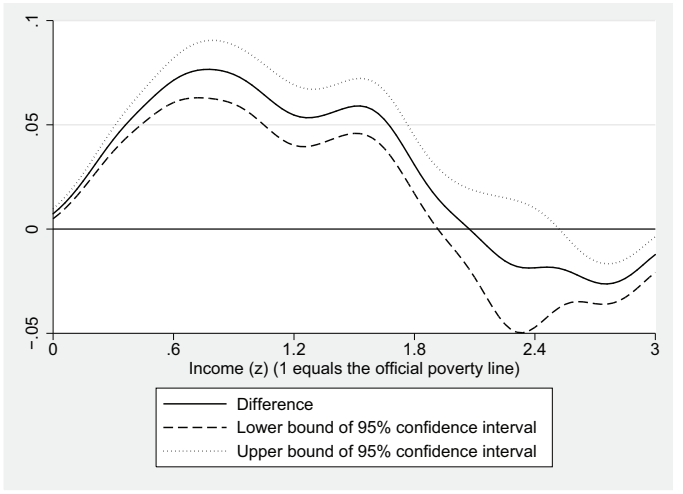

Figure 8: The ratio between pro-poor consumption dominance curves

$$
\delta_{\text {Food,Energy }}^{R: s=1}(z)
$$

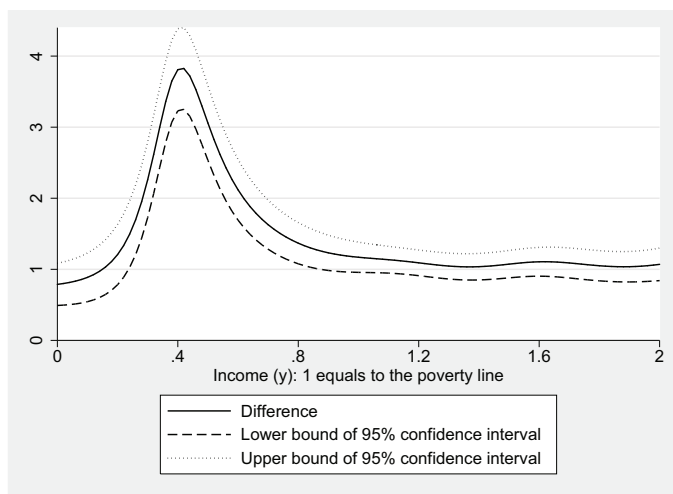

$\delta_{\text {Food,Energy }}^{A: s=1}(z)$

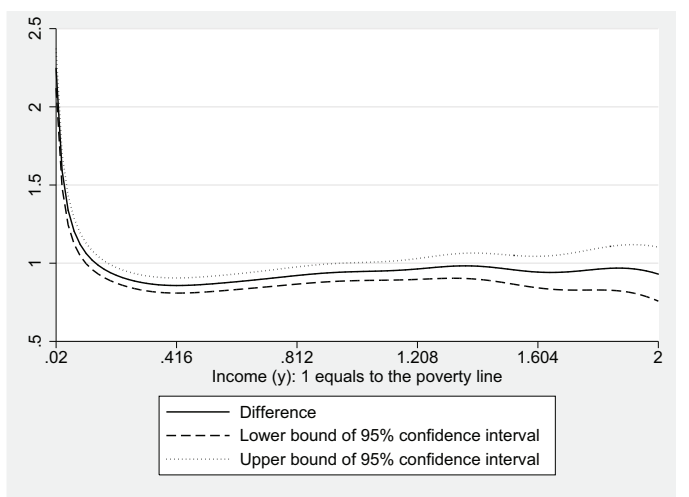




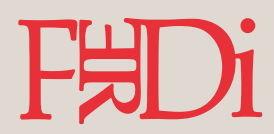

Créée en 2003, la Fondation pour les études et recherches sur le développement international vise à favoriser la compréhension du développement économique international et des politiques qui l'influencent.

\section{Contact}

www.ferdi.fr

contact@ferdi.fr

+33 (o)4 73177530 